\title{
Vertical observations of the atmospheric boundary layer structure over Beijing urban area during air pollution episodes
}

\author{
Linlin Wang ${ }^{1,2}$, Junkai Liu ${ }^{1,5}$, Zhiqiu Gao ${ }^{1}$, Yubin Li $^{2}$, Meng Huang ${ }^{2}$, Sihui Fan ${ }^{2}$, Xiaoye Zhang ${ }^{3}$, Yuanjian Yang ${ }^{2,6}$, \\ Shiguang Miao ${ }^{4}$, Han Zou ${ }^{1}$, Yele Sun ${ }^{1}$, Yong Chen ${ }^{1}$, and Ting Yang ${ }^{1}$ \\ ${ }^{1}$ State Key Laboratory of Atmospheric Boundary Layer Physics and Atmospheric Chemistry (LAPC), Institute of \\ Atmospheric Physics, Chinese Academy of Sciences, Beijing 100029, China \\ ${ }^{2}$ Collaborative Innovation Centre on Forecast and Evaluation of Meteorological Disasters, School of Atmospheric Physics, \\ Nanjing University of Information Science and Technology, Nanjing, 210044, China \\ ${ }^{3}$ Chinese Academy of Meteorological Sciences, Beijing, 100081, China \\ ${ }^{4}$ Institute of Urban Meteorology, China Meteorological Administration, Beijing, 100081, China \\ ${ }^{5}$ University of Chinese Academy of Sciences, Beijing 100049, China \\ ${ }^{6}$ State Key Laboratory of Loess and Quaternary Geology, Institute of Earth Environment, Chinese Academy of Sciences, \\ Xi'an 710061, China
}

Correspondence: Zhiqiu Gao (zgao@mail.iap.ac.cn)

Received: 12 November 2018 - Discussion started: 15 January 2019

Revised: 15 April 2019 - Accepted: 17 April 2019 - Published: 23 May 2019

\begin{abstract}
We investigated the interactions between the air pollutants and the structure of the urban boundary layer (UBL) over Beijing by using the data mainly obtained from the $325 \mathrm{~m}$ meteorological tower and a Doppler wind lidar during 1-4 December 2016. Results showed that the pollution episodes in this period could be characterized by low surface pressure, high relative humidity, weak wind, and temperature inversion. Compared with a clean daytime episode that took place on 1 December, results also showed that the attenuation ratio of downward shortwave radiation was about $5 \%, 24 \%$ and $63 \%$ in afternoon hours (from 12:00 to 14:00 local standard time, LST) on 2-4 December, respectively, while for the net radiation $\left(R_{\mathrm{n}}\right)$ attenuation ratio at the $140 \mathrm{~m}$ level of the $325 \mathrm{~m}$ tower was $3 \%, 27 \%$ and $68 \%$. The large reduction in $R_{\mathrm{n}}$ on 4 December was not only the result of the aerosols, but also clouds. Based on analysis of the surface energy balance at the $140 \mathrm{~m}$ level, we found that the sensible heat flux was remarkably diminished during daytime on polluted days and even negative after sunrise (about 07:20 LST) till 14:00 LST on 4 December. We also found that heat storage in the urban surface layer played an important role in the exchange of the sensible heat flux. Owing to the advantages of the wind lidar having superior spatial and temporal resolution, the vertical velocity variance could capture
\end{abstract}

the evolution of the UBL well. It clearly showed that vertical mixing was negatively related to the concentrating of pollutants, and that vertical mixing would also be weakened by a certain quantity of pollutants, and then in turn worsened the pollution further. Compared to the clean daytime on 1 December, the maximums of the boundary layer height (BLH) decreased about $44 \%$ and $56 \%$ on 2-3 December, when the average $\mathrm{PM}_{2.5}\left(\mathrm{PM}_{1}\right)$ concentrations in afternoon hours (from 12:00 to 14:00 LST) were $44(48) \mathrm{g} \mathrm{m}^{-3}$ and $150(120) \mu \mathrm{g} \mathrm{m}^{-3}$. Part of these reductions of the BLH was also contributed by the effect of the heat storage in the urban canopy.

\section{Introduction}

In recent years, fine particulate matter $(\mathrm{PM})$ pollution events in the atmospheric boundary layer (ABL), i.e., involving particles with diameters $\leq 2.5 \mu \mathrm{m}\left(\mathrm{PM}_{2.5}\right)$, have occurred frequently in urban areas, thus emerging as a serious environmental issue in China. The Beijing-Tianjin-Hebei (BTH) metroplex region is one of the most seriously affected areas in China with respect to air pollution. The main hazards or negative effects of air pollution generally fall into two cat- 
egories: human health and traffic. Thus, it is an issue that has attracted considerable public attention and, accordingly, numerous studies have focused on investigating the sources and formation mechanisms of air pollution in the BTH region, through numerical simulation and field observational methods (e.g., L. T. Wang et al., 2013; Sun et al., 2014; Ye et al., 2016; X. Li et al., 2017; Han et al., 2018).

Beijing, the main city of the BTH region, has experienced several high-impact, persistent, and severe air pollution episodes in recent years, with notable examples having taken place in January 2013, October and November 2014, December 2015 and 2016, and January 2017. Beijing is located in the North China Plain (NCP), and is surrounded by the Yan and Taihang mountains from north to west. Therefore, Beijing is frequently affected by thermally induced mountain-plain wind circulation over the NCP, which contributes to the transportation of air pollution in Beijing (Liu et al., 2009; Hu et al., 2014; Chen et al., 2017; Zheng et al., 2018). In addition, it is well recognized that high levels of anthropogenic emissions and rapid formation of secondary aerosol are key factors leading to the frequent occurrence of severe haze episodes (Z. Li et al., 2017). More importantly, these interactions on local and large scales are associated with the meteorological conditions (Sun et al., 2013; Yang et al., 2018). Previous studies have reported that heavy pollution in Beijing is highly related to unfavorable local weather conditions, such as weak wind, strong temperature inversion, high relative humidity (RH) and low surface pressures (Zhang et al., 2014; Liu et al., 2017; Li et al., 2018).

Many studies have also suggested that the structure of the urban boundary layer (UBL), in particular wind, turbulence and stability, had strong influence on the occurrence, maintenance and vertical diffusivity of air pollutants (Han et al., 2009; Zhao et al., 2013). For instance, emissions of air pollution in urban areas lead to a buildup of pollutant concentrations due to reduced mixing and dispersion in the UBL (Holmes et al., 2015). An analysis of the dramatic development of a severe air pollution event on November 2014 in the Beijing area revealed that turbulent mixing played an important role in transporting the heavily polluted air and $\mathrm{PM}_{2.5}$ oscillations ( $\mathrm{Li}$ et al., 2018). The vertical profiles of wind and temperature along with the BLH are the main factors affecting turbulence diffusion. Moreover, the BLH is also a key variable in describing the structure of UBL and in predicting air pollution (Stull, 1988; Miao et al., 2011; Barlage et al., 2016). Miao et al. (2018) found that the concentration of $\mathrm{PM}_{2.5}$ anticorrelates with the BLH. In addition, air pollutants can also modulate radiative transfer processes through the scattering, reflection and absorption of shortwave radiation and reflection and absorption and emission of longwave radiation (Dickerson et al., 1997; Stone et al., 2008; Wang et al., 2017). In response to reduced solar radiation, the cooling of surface air temperature can lead to strong temperature inversion in the near-surface layer, which can increase the atmospheric stability and prolong the accumu- lation of pollution because of the existence of this stable boundary layer (Barbaro et al., 2013; Che et al., 2014; Gao et al., 2015). A positive feedback loop in which more aerosol loading leads to a more stable atmospheric boundary layer (ABL), enhanced accumulation of pollutants within the ABL and a more polluted and hazier atmosphere was described by Zhang et al. (2013, 2018). It is also found that the further worsened meteorological conditions caused by cumulated aerosol pollution subsequently occurred "explosive growth" of $\mathrm{PM}_{2.5}$ mass, which often appears in the late stage of a heavy aerosol pollution episode in Beijing-Tianjin-Hebei area in China (Zhong et al., 2017).

Although many studies have provided various interesting findings, consensus has not been reached on the pollutant transport mechanism and the nature of the interactions between the air pollution and the structure of the UBL, mainly due to a lack of reliable and detailed field measurements and the complex properties of the UBL. Additionally, as mentioned above, there are several factors that affect the occurrence of urban air pollution, which can lead to different pollutant transporting mechanism characteristics for different pollution events. Therefore, taking a severe heavy pollution event that occurred during 1-4 December 2016 in the Beijing as an example, we will aim to investigate evolution characteristics of ABL structure and further explore the interaction between the structure of the UBL and the air pollution by using the field data collected from a $325 \mathrm{~m}$ meteorology tower in Beijing urban area, as well as from a Doppler wind lidar and a dual-wavelength (1064 and $532 \mathrm{~nm}$ ) depolarization lidar. During this pollution episode, the $\mathrm{PM}_{2.5}$ concentration rapidly increased from about $100 \mu \mathrm{g} \mathrm{m}^{-3}$ to approximately $500 \mathrm{\mu g} \mathrm{m}^{-3}$ at 12:00 LST on 4 December, which can be considered a typical case to achieve a better understanding of the formation, transportation and dispersion mechanisms of the similar pollution event, as well as the interactions between the air pollution and the structure of the UBL.

The paper is organized as follows: Sect. 2 describes the field site, data and methods. The overall characteristics of the synoptic pattern and the meteorological factors related to the development of the pollution event are investigated in Sect. 3 . The impacts of the vertical UBL structure evolution on this pollution episode, and vice versa - especially the turbulence due to the radiative forcing of aerosols - are also explored in Sect. 3. Lastly, the results of the study are summarized in Sect. 4.

\section{Materials}

\subsection{Site and data}

The main data used in this study were from a tall tower in Beijing, officially known as "the Beijing $325 \mathrm{~m}$ meteorological tower", which is located at an urban site in the city $\left(39.97^{\circ} \mathrm{N}, 116.37^{\circ} \mathrm{E}\right.$; the Beijing "inner-city" site). Within a 
radius of $5 \mathrm{~km}$ of the tower, buildings of different heights are distributed irregularly in all directions, and the area is surrounded by four-story to 20-story buildings with heights of 10-60 $\mathrm{m}$ (Liu et al., 2017). The surrounding buildings can be seen in Fig. 1a. This tall tower conducts turbulent flux measurements using sonic anemometers (WindMaster Pro, Gill, UK) at three different levels (i.e., 47, 140 and $280 \mathrm{~m}$ ). Note that CSAT3 three-dimensional sonic anemometers designed by Campbell Scientific Inc. (USA) at these three levels have been replaced by the WindMaster Pro since 2015, so the turbulence measurements before 2015 used in previous papers were collected using the CSAT3 sonic anemometers. The new sonic anemometer experimental setup has been reported by Cheng et al. (2018). Downward-pointing and upward-pointing pyrgeometers and pyranometers (CNR1, Kipp \& Zonen) are maintained at the same heights as the sonic anemometers to measure four-component radiation (i.e., incoming shortwave and longwave radiation and outgoing shortwave and longwave radiation). Meteorological elements, including wind speed, wind direction (010C cup anemometers and $020 \mathrm{C}$ wind vanes, Met One, USA), RH and temperature (HC2S3, Rotronic, Switzerland) are measured at 15 levels (i.e., 8, 15, 32, 47, 65, 80, 100, 120, 140, 160, 180, 200, 240, 280 and $320 \mathrm{~m}$ ) above ground level. An Aerodyne aerosol chemical speciation monitor and a high-resolution time-of-flight aerosol mass spectrometer were deployed at $260 \mathrm{~m}$ and ground level, repetitively to measure $\mathrm{PM}_{1}$ mass concentrations at $5 \mathrm{~min}$ intervals (Sun et al., 2016).

In addition, wind speed (05103-L, R. M. Young) and temperature (HMP45C, Vaisala) at the $2.2 \mathrm{~m}$ level are measured at a surface station about $20 \mathrm{~m}$ south of the tower. We also used wind data collected above $100 \mathrm{~m}$ by a Doppler wind lidar (Windcube 200, Leosphere, Orsay, France) situated on the rooftop of a $8 \mathrm{~m}$ high building. Furthermore, a dualwavelength (1064, and $532 \mathrm{~nm})$ depolarization lidar developed by the National Institute for Environmental Studies, Japan, sits on the rooftop of a $28 \mathrm{~m}$ high building (Yang et al., 2017), which provided us with information on aerosols at a higher layer. The mass concentrations of $\mathrm{PM}_{2.5}$ measured at the Beijing Olympic Sports Center (Aoti surface station) of the National Air Quality Monitoring Network of China using tapered element oscillating microbalance analyzers with hourly monitored readings were obtained from the website of the China National Environmental Monitoring Center (http: //106.37.208.233:20035/, last access: 8 May 2019).

The three-dimensional sonic anemometers' original records $(10 \mathrm{~Hz})$ were processed prior to analysis using the methods of double rotation (i.e., yaw and pitch rotations) and linear detrending. L. L. Wang et al. (2014) tested a few averaging periods and found that a $1 \mathrm{~h}$ averaging period is reasonable at this urban site. The processing of turbulence data in our study followed the method described by L. L. Wang et al. (2014).

The criterion of threshold carrier-to-noise ratio (CNR) was used to reduce the effects of invalid data on profiles derived from the Doppler velocities. The data control process was described in detail by Huang et al. (2017). We calculated the vertical velocity variance and stream-wise wind speed and wind direction over a 30 min segment.

The dual-wavelength depolarization lidar was used to retrieve the aerosol vertical structure at a spatially resolved resolution of $6 \mathrm{~m}$ and temporally resolved resolution of $10 \mathrm{~s}$, but only for altitudes in excess of $100 \mathrm{~m}$ because of an incomplete overlap between the telescopic field of view and the laser beam. For this study the raw temporal resolution of the retrieved aerosol profiles was set at $30 \mathrm{~min}$. More details on the lidar instruments and various data processing techniques were provided by Yang et al. (2017).

The NCEP FNL (Final) Operational Global Analysis data collected every $6 \mathrm{~h}$, at 02:00, 08:00, 14:00 and 20:00 LST, on $1^{\circ} \times 1^{\circ}$ grids were used to analyze the synoptic-scale weather conditions.

\subsection{Methods}

\subsubsection{Turbulent flux and radiation calculation}

The sensible heat and latent heat fluxes were calculated using the eddy-covariance method:

$H=\rho C_{\mathrm{p}} \overline{w^{\prime} T^{\prime}}$,

$\mathrm{LE}=L_{\mathrm{v}} \overline{w^{\prime} q^{\prime}}$,

where $\rho$ is the air density $\left(\mathrm{kg} \mathrm{m}^{-3}\right), C_{\mathrm{p}}$ is the specific heat capacity at constant pressure $\left(\mathrm{J} \mathrm{kg}^{-1} \mathrm{~K}^{-1}\right), w$ is the vertical velocities $\left(\mathrm{m} \mathrm{s}^{-1}\right)$ from the sonic anemometers, $T$ is the air temperature $(\mathrm{K}), L_{\mathrm{v}}$ is the latent heat of vaporization of water $\left(\mathrm{J} \mathrm{kg}^{-1}\right)$ and $q$ is the specific humidity $\left(\mathrm{kg} \mathrm{kg}^{-1}\right)$. The overbar denotes time averages and an averaging period of $60 \mathrm{~min}$ was used in this study.

The surface energy budget (SEB) without consideration of horizontal advection is usually formulated as

$R_{\mathrm{n}}+Q_{\mathrm{F}}=H+\mathrm{LE}+G$,

where $H$ is the sensible heat flux from the surface to the adjacent air, LE is the latent heat flux into the atmosphere associated with evapotranspiration, and $G$ is the ground and urban canopy heat storage. $R_{\mathrm{n}}$ is the net radiation, which can be described as

$R_{\mathrm{n}}=\mathrm{DSR}-\mathrm{USR}+\mathrm{DLR}-\mathrm{ULR}$.

DSR stands for downward shortwave radiation, USR for upwelling short-wave radiation, DLR for downward incoming long-wave radiation and ULR for upwelling long-wave radiation. The anthropogenic heat flux $\left(Q_{\mathrm{F}}\right)$ is a significant term in urban areas, which is the additional energy released by human activities; however its estimation is difficult due to the absence of accurate energy consumption and traffic flow data. In this study, the heat storage term minus the anthropogenic heat flux, $G-Q_{\mathrm{F}}=R_{\mathrm{n}}-H-\mathrm{LE}$, will be analyzed 


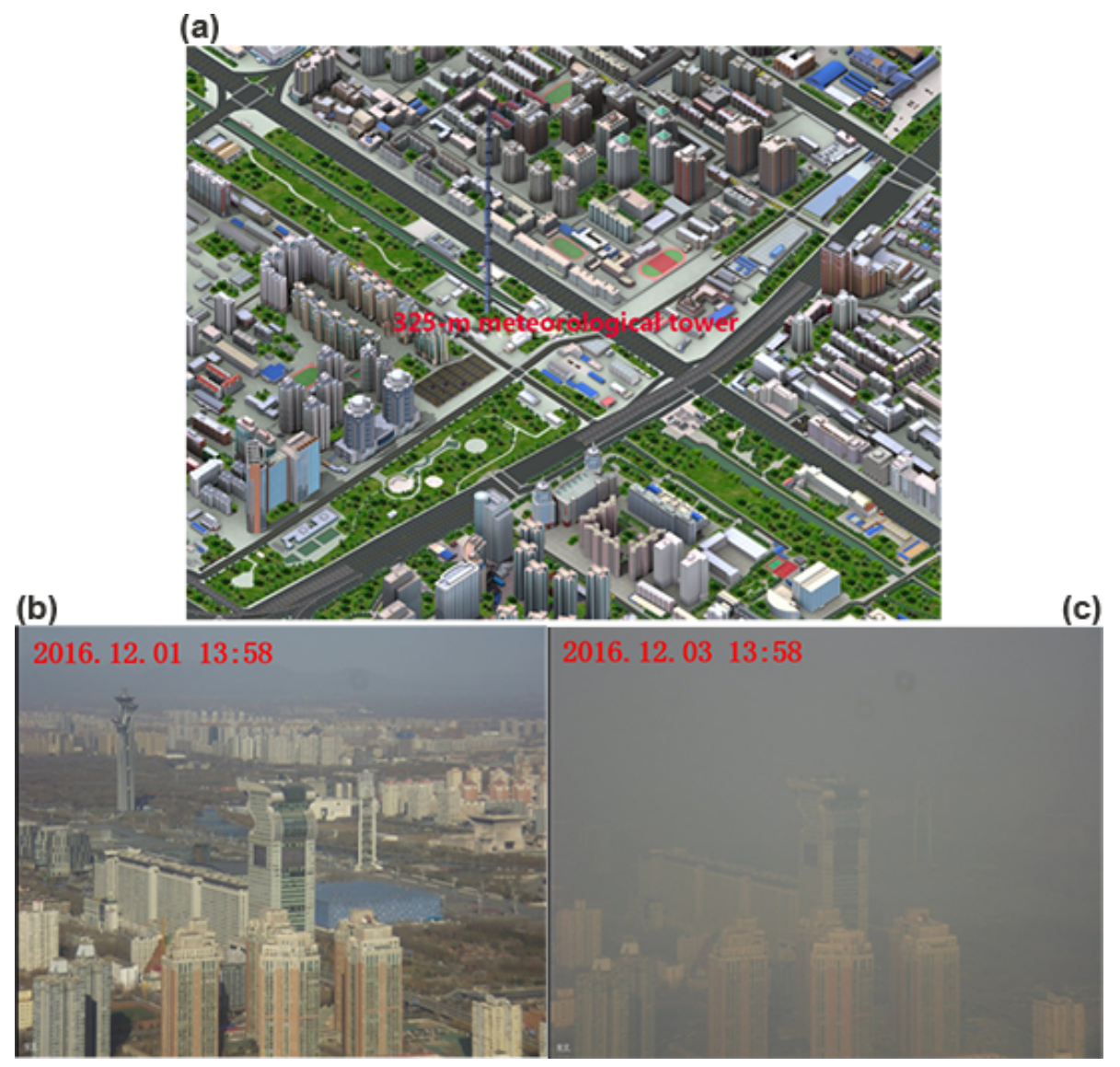

Figure 1. (a) Three-dimensional graph of the underlying surface around the $325 \mathrm{~m}$ tower in Beijing. Photographs of the buildings looking north from the $280 \mathrm{~m}$ level of the $325 \mathrm{~m}$ tower at 13:58 LST: (b) 1 December and (c) 3 December 2016.

\subsubsection{Determination of UBL depths}

Lidar techniques have become one of the most valuable and popular systems to detect the atmosphere because of their higher spatiotemporal resolution. As a result, many techniques have been developed to determine the BLH by using remote-sensing instruments, such as radar wind profilers, aerosol lidars and ground-based microwave radiometers (Flamant et al., 1997; Emeis et al., 2004; Haman et al., 2012). Remote sensing is particularly useful in analyzing vertical profiles of turbulence mixing in UBL, and is generally easier to deploy than radiosondes (Georgoulias et al., 2009).

Recently, a turbulence method to define the BLH has been proposed by using the Doppler lidar, which can obtain threedimensional wind. The vertical velocity variance $\sigma_{w}^{2}$ can be used to describe the density of the turbulence; hence the height of the layer in which vertical velocity variance $\sigma_{w}^{2}$ exceeds a given threshold is considered the BLH. Previous investigators have given different values of $\sigma_{w}^{2}$ for different underlying surfaces (Tucker et al., 2009; Pearson et al., 2010). Barlow et al. (2015) defined the mixing height as the height over London, UK, up to which $\sigma_{w}^{2}>0.1 \mathrm{~m}^{2} \mathrm{~s}^{-2}$. Here, we select this method of Barlow et al. (2011), because of the similar urban fraction between central Beijing and London.

The 30 min vertical velocity standard deviation between lidar is

$\sigma_{w}=\sqrt{\frac{1}{N-1} \sum_{i=1}^{N}\left(w_{i}-\bar{w}\right)^{2}}$,

where $N$ is the record number every $30 \mathrm{~min}, w_{i}$ denotes the $i$ th vertical velocity $\left(\mathrm{m} \mathrm{s}^{-1}\right)$ and $\bar{w}$ is the mean vertical wind speed.

\section{Results and discussion}

\subsection{Air pollution episodes in Beijing}

As shown in Fig. 1c, the visibility around the $325 \mathrm{~m}$ tower at about 14:00 LST on 3 December was much lower than that on 1 December. In fact, the visibility decreased rapidly from 12:00 to 16:00 LST before sunset (16:50 LST) on 3 December, accompanied by the increasing $\mathrm{PM}_{2.5}$ concentration (from 100 to $200 \mu \mathrm{g} \mathrm{m}^{-3}$ ) at the Olympic Sports Center station and $\mathrm{PM}_{1}$ concentration (from 100 to $190 \mu \mathrm{g} \mathrm{m}^{-3}$ ) at the 


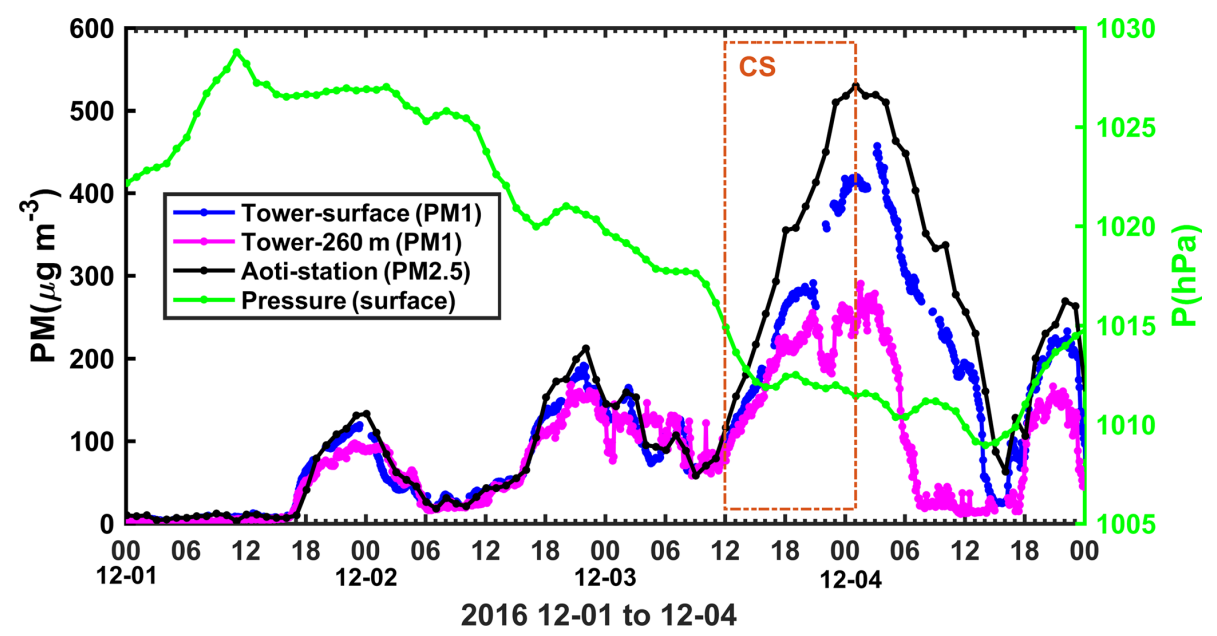

Figure 2. Temporal variation in the $\mathrm{PM}_{1}$ observed at the surface and the $260 \mathrm{~m}$ level of the $325 \mathrm{~m}$ tower, $\mathrm{PM}_{2.5}$ at Aoti surface station, and surface pressure at the surface station of the IAP, during 1-4 December 2016 (red box: CS).

$325 \mathrm{~m}$ tower station (Fig. 2). After sunset, the $\mathrm{PM}_{2.5}$ hourly maximum concentration reached $530 \mu \mathrm{g} \mathrm{m}^{-3}$ at 02:00 LST, 4 December. The cumulative explosive growth process of the pollution, starting at 12:00 LST, 3 December, and lasting till 02:00 LST, 4 December, is defined as the cumulative stage (CS).

The surface pressure measured at the Institute of Atmospheric Physics (IAP) surface station (Fig. 2) indicated the air quality was getting worse with decreasing surface pressure. In order to analyze the synoptic background fields for the CS, the sea level pressure and surface wind field on 3 December are shown in Fig. 3. At 08:00 LST, the Beijing region was governed by a saddle-type pressure field characterized by uniform pressure, very weak wind speed and changeable wind direction. The surface high-pressure system over the Bohai and Yellow seas was conducive to the maintenance of these stagnant meteorological conditions till 14:00 LST, which provided unfavorable meteorological conditions for the diffusion of air pollutants and contributed to the formation of CS.

\subsection{Meteorological parameters}

As shown in Fig. 4a, RH was mostly larger than $40 \%$ during pollution episodes, and increased along with the concentrated $\mathrm{PM}_{2.5}\left(\mathrm{PM}_{1}\right)$. Especially during the $\mathrm{CS}$, $\mathrm{RH}$ could reach close to $100 \%$ at nighttime, which firstly appeared at the levels of 160-220 m and then extended to the lower levels. Meanwhile, the deeper RH (>80\%) with higher PM concentrations during the CS was possibly caused by secondary aerosol formation. Due to aerosol cooling force, $\theta$ in the daytime on 3 December was much lower than on other days. Clearly, the wind flow played an important role in the air pollution process. The southwesterly wind transported air pollutants from Hebei Province to Beijing on the first two pollution nights (Fig. 4c). In order to investigate the charac- teristics of the UBL structure, the vertical gradients of potential temperature $\left(\Delta \theta=\theta_{2}-\theta_{1}\right)$ and gradient absolute values in wind speed $\left(|\Delta U|=\left|U_{2}-U_{1}\right|\right)$ were calculated by using the adjacent two levels as the thermal and dynamic factors (Fig. 5). It was found that the vertical gradients of wind speed and potential temperature were small because of strong vertical thermal mixing during daytime, whereas they were large at nighttime due to weak vertical mixing. Temperature inversions were found during all three nights, which was negative to the dispersion of the pollutants $(\mathrm{Li}$ et al., 2018; Wang et al., 2019). Typically, the formation of temperature inversions in winter at night is associated with the radiative cooling effect. Zhong et al. (2019) found that the temperature reduction because of the aerosol cooling force during daytime induced or reinforced an inversion, and then these enhanced inversions further worsen the aerosol pollution. This two-way feedback mechanism between unfavorable meteorological conditions and cumulative aerosol pollution also appeared in our case. The values of $\Delta \theta$ and the duration of $\Delta \theta>0$ increased day by day, meaning the thermal stability strengthened with worsening polluted days. Moreover, a long-term existence of temperature inversion near the surface could be found till 12:00 LST, 4 December, associated with extremely steady stability. This stable surface stratification resulted in the suppressed diffusion of air pollutants at the surface, causing a dissipation lag for $\mathrm{PM}_{1}$ at the surface compared to the case at the $260 \mathrm{~m}$ level (shown in Fig. 2).

Owing to the limited height of the tower, the wind profile above several hundred meters collected by the Doppler lidar (Fig. 6) can be used to further investigate the association between the wind flow and air pollution process. On 1 December, the air quality was good before noon and there was strong northwest wind (mostly around $10 \mathrm{~m} \mathrm{~s}^{-1}$ ) at $200-1000 \mathrm{~m}$ above ground level (a.g.l.). In our case, notably, a low-level jet (LLJ) established after sunset, with the 

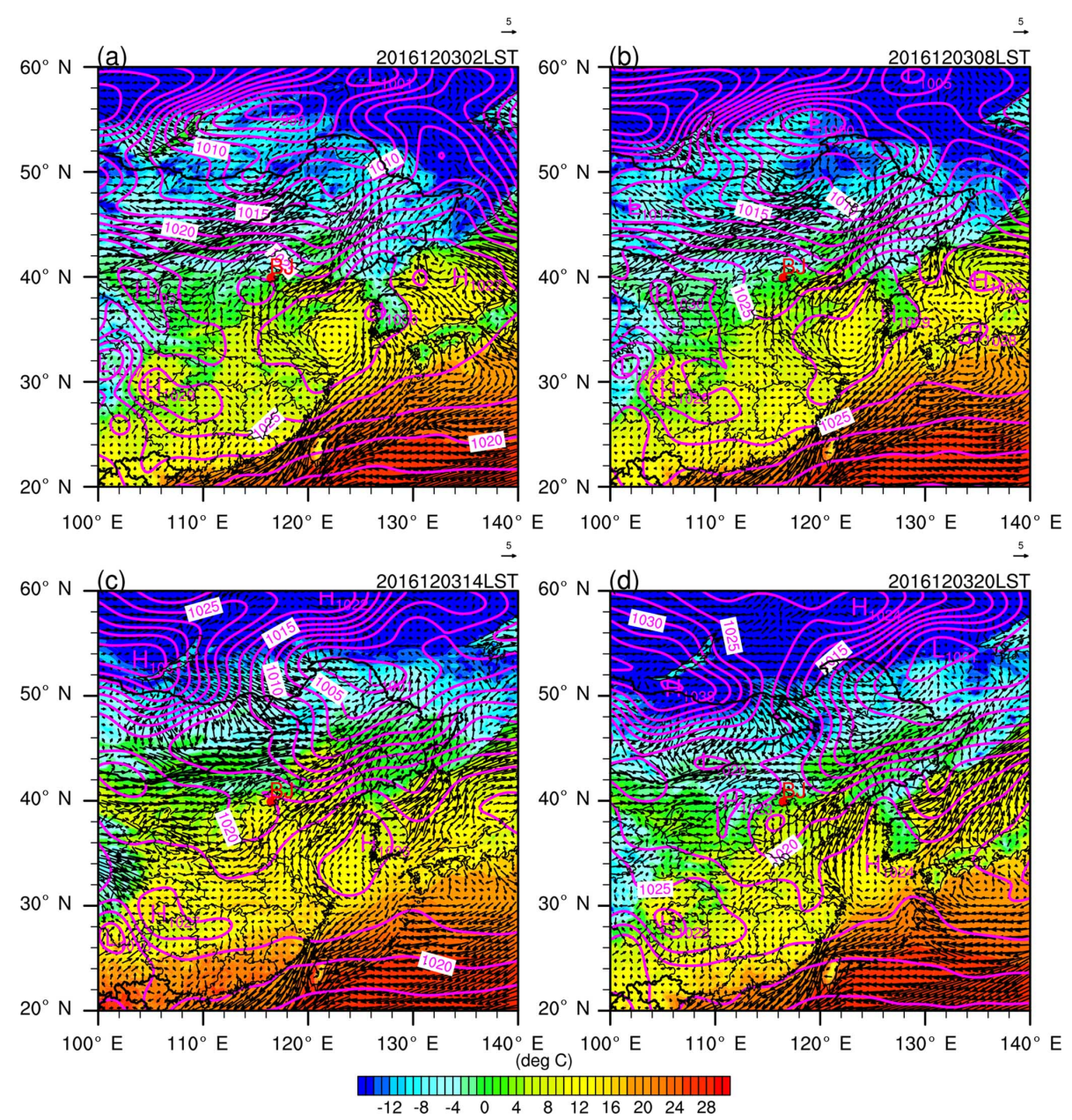

Figure 3. Distribution of surface pressure and temperature at (a) 02:00 LST, (b) 08:00 LST, (c) 14:00 LST and (d) 20:00 LST, 3 December 2016, where the green star marks the location of Beijing (BJ).

jet core at 300-500 m a.g.l., and the maximum wind speed was around $10 \mathrm{~m} \mathrm{~s}^{-1}$ at about 24:00LST. We can see the $\mathrm{PM}_{2.5} / \mathrm{PM}_{1}$ concentration was starting to increase after sunset with the maximum $\mathrm{PM}_{2.5}$ concentration $\left(120 \mu \mathrm{g} \mathrm{m}^{-3}\right)$ observed at 24:00 LST, and then decreased with the gradually weakened LLJ, which suggests this southwesterly LLJ transferred polluted air from the south by advection to Beijing before midnight. A previous study also reported that presence of an LLJ can increase the surface pollution through horizontal advection (Hu et al., 2013). In addition to the horizontal advection, LLJ can also generate vertical mixing due to the wind shear with large $|\Delta U|\left(>1 \mathrm{~m} \mathrm{~s}^{-1}\right)$. Once the northern mountain flow was generated, the LLJ became weaker $\left(<5 \mathrm{~m} \mathrm{~s}^{-1}\right)$ in the early morning on 2 December, and then the vertical mixing generated by the weakened LLJ changed to the dominated term, which made an important contribution to the mixing of the pollutants in the dissipated period. Chen et al. (2018) also pointed out that a northerly weak LLJ noticeably reduced the PM concentration in urban Beijing. As a result, the presence of an LLJ has an indispensable effect on the process of the air pollution in the nocturnal boundary layer (NBL).

We can also see that the $\mathrm{PM}_{1}$ concentration at the $260 \mathrm{~m}$ level started to decrease at 02:00 LST, 2 December, which was about $2 \mathrm{~h}$ later than $\mathrm{PM}_{1}$ at the ground level. This could be explained that the gradually deep and clean northwest mountain-plain wind occurred first below $100 \mathrm{~m}$ a.g.l., and then reached the upper level. On 2 December, the wind below $1 \mathrm{~km}$ was dominated by speeds of around $2 \mathrm{~m} \mathrm{~s}^{-1}$ from 06:00 to 22:00 LST. The weak northerly winds did not fully disperse the air pollutants before noon. Meanwhile, after the transition time on 13:00LST, southerly winds existed and brought polluted air from the south, and then the air quality became worsened, and the maximum $\mathrm{PM}_{2.5}$ concentration $\left(210 \mu \mathrm{g} \mathrm{m}^{-3}\right)$ occurred at 22:00 LST. Compared to early morning on 2 December, the wind below $600 \mathrm{~m}$ was weaker and the vertical gradients (Fig. 6b) were much smaller, meaning mechanical turbulence (vertical mixing) was extremely weak. Thus, there is no dramatic reduction in the air pollution before sunrise on 3 December, and then the CS began at 

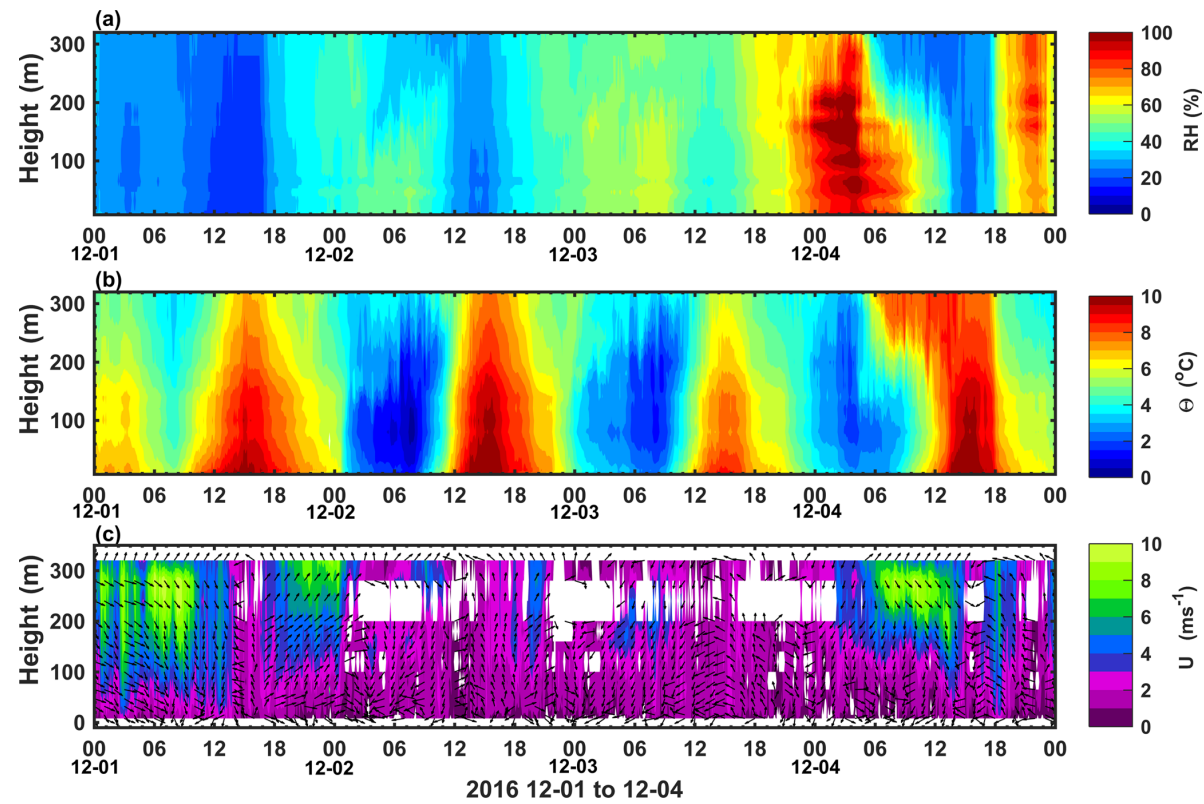

Figure 4. Vertical evolution of (a) relative humidity, (b) virtual temperature, and (c) wind speed and wind vectors (arrows), observed at 15 levels of the $325 \mathrm{~m}$ tower during 1-4 December 2016.

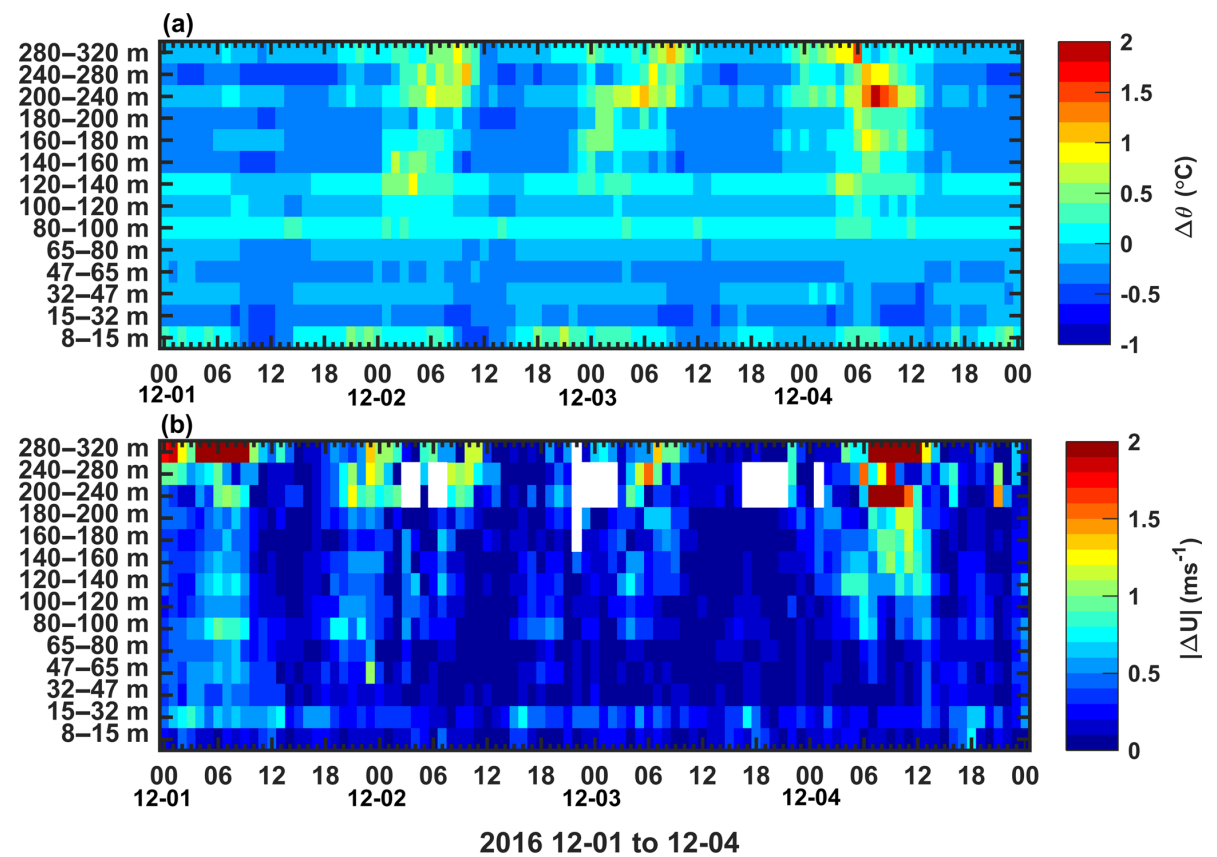

Figure 5. Vertical evolution of (a) vertical gradients of relative potential temperature and (b) vertical gradients of zonal wind speed, based on observations at 15 levels of the $325 \mathrm{~m}$ tower during 1-4 December 2016.

noon when the wind speeds were mostly lower than $3 \mathrm{~m} \mathrm{~s}^{-1}$ below $1 \mathrm{~km}$ a.g.l. because of the saddle-type pressure-field background (Fig. 3).

\subsection{SEB characteristics}

Solar radiation is the most important driver of the development of the UBL. Various climatic changes within the urban $\mathrm{ABL}$ are driven by the SEB, which distributes the energy by radiation, convection and conduction between a facet (Oke et al., 2017). Therefore, the SEB, described as Eq. (3), is a 


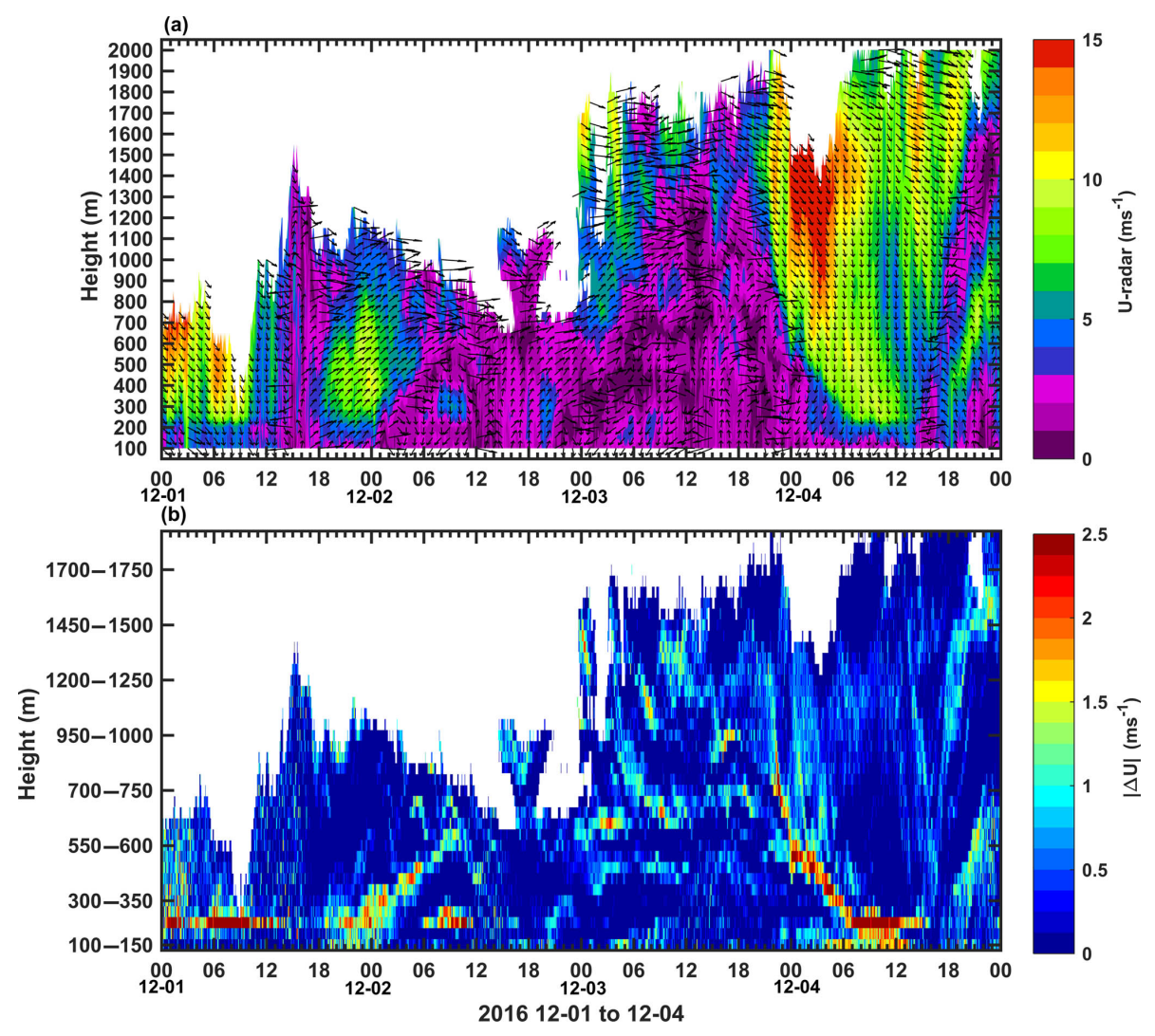

Figure 6. Vertical evolution of (a) wind speed and (b) vertical gradients of wind speed, based on Doppler wind lidar observations during 1-4 December 2016.

fundamental aspect contributing to our understanding of the variations in the UBL.

In this study, we wanted to focus on the SEB at one level rather than the vertical difference between different levels. Moreover, measurements at $140 \mathrm{~m}$ are above the roughness sublayer layer and are within the surface layer (Miao et al., 2012); hence only the observations at the $140 \mathrm{~m}$ level were used in studying the radiative exchange. In Fig. 7, the four components show the daytime pollution received less shortwave radiation but more longwave radiation than the daytime clean episode. The DSR reduces with gradually worsening air quality on a day-to-day basis. The DSR during this $4 \mathrm{~d}$ period reached a peak value $\left(482 \mathrm{~W} \mathrm{~m}^{-2}\right)$ at 12:00 LST, 1 December. The differences between the daytime clean and pollution episodes reached about 20, 110 and $376 \mathrm{~W} \mathrm{~m}^{-2}$ at 12:00 LST on 2-4 December, respectively. Overall, compared with the DSR during the daytime clean episode on 1 December, the attenuation ratio of the DSR was about $4 \%, 23 \%$ and $78 \%$ at 12:00 LST, 3-4 December, and the averaged value was $5 \%, 24 \%$ and $63 \%$ in afternoon hours (12:00-14:00 LST), respectively. Many efforts have been made on the radiative forcing due to the increasing aerosol loading by using model simulations and field experiments (Ramanathan et al., 2001; Xia et al., 2007; Ding et al.,
2016). Based on observations at the $140 \mathrm{~m}$ level at the $325 \mathrm{~m}$ tower under 8 cloudless days ( 3 clean days and 5 pollution days) in January 2015, Wang et al. (2016) found that the maximum attenuation of the DSR was $33.7 \mathrm{~W} \mathrm{~m}^{-2}$ and the attenuation ratio was $7.4 \%$ at 12:00 LST. Due to the difference in solar angle, degree of pollution, pollutant component, cloud, etc., attenuation differences are expected in different case studies. Here, the USR on clean days was larger than on pollution days with a larger maximum difference $\left(32 \mathrm{~W} \mathrm{~m}^{-2}\right)$ on 4 December, which was mainly caused by the lower quantity of DSR received on 4 December. For the DLR, the diurnal change in the difference between 1 and 2 December was insignificant. During the other two day times, the DLR increased with the enhancement of pollution level, and the peak values on 3 December and 4 December were respectively 51 and $56 \mathrm{~W} \mathrm{~m}^{-2}$.

The diurnal variation in the DSR on 4 December was discontinuous, which suggests the large attenuation of the DSR on this day was not only the impact of the higher aerosol concentrations, but also that of the cloud cover. The largest DLR on 4 December also indicated the possible existence of clouds. Information on the coverage of clouds can be seen from satellite cloud images, which in this case were provided by the products of the Himawari- 8 geostationary me- 

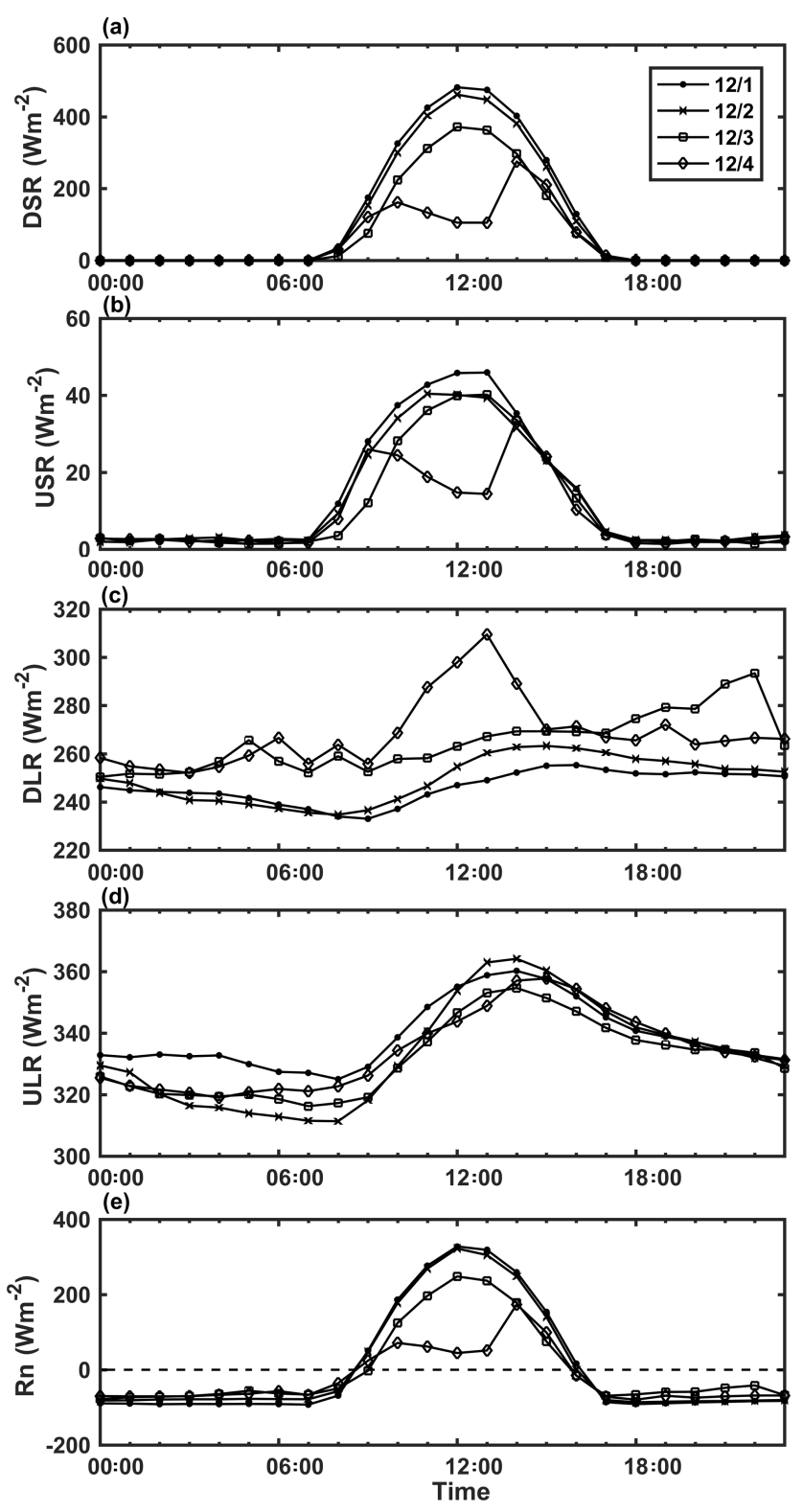

Figure 7. Diurnal cycle of (a) downward shortwave radiation, (b) upward shortwave radiation, (c) downward longwave radiation, (d) upward longwave radiation and (e) net radiation, observed at the $140 \mathrm{~m}$ level of the $325 \mathrm{~m}$ tower during 1-4 December 2016.

teorological satellite, launched by the Japan Meteorological Agency (http://www.eorc.jaxa.jp/ptree/, last access: 25 October 2018). According to these data, the first $3 \mathrm{~d}$ were free from clouds (figures are omitted). From the mass of grey marked by the red square in Fig. 8, it is apparent that pollutants dominated the BTH region at 08:00 LST, and then this area became partially cloudy. The area over Beijing was covered with cloud at 10:00 LST, which lasted about $3 \mathrm{~h}$, and then at 15:00 LST had become cloudless. Van de Heever and Cotton (2007) found giant nuclei could lead to strong early enhancement of cloud development. Moreover, pre- vious studies have found that cloud fraction changes with aerosol loading (Gunthe et al., 2011; Che et al., 2016). In our case, before the cloudy day, heavy pollutants occurred over the BTH region, and the IAP station recorded high relative humidity ( $>90 \%$, shown in Fig. 4 ) at midnight, which would have enhanced aerosol hygroscopic growth, implying significant aerosol-cloud interactions, referred to in Che et al. (2016). Thus, we can deduce that the cloud cover over the BTH region may in part account for the aerosols on the pollution days, which supports the abundant cloud condensation nuclei (CNN) for the cloud formation on the following day. Certainly, further studies with more measurement data and model simulations are needed to validate this conclusion.

In general, the $R_{\mathrm{n}}$ (shown in Fig. 7) attenuation ratio was $3 \%, 27 \%$ and $68 \%$, in the afternoon hours, 2-4 December. This attenuation of the radiation on pollution days directly resulted in the change of the SEB. In Fig. 9, clearly, LE was extremely low, less than $50 \mathrm{~W} \mathrm{~m}^{-2}$ during this $4 \mathrm{~d}$ period in winter. The peak value of $H$ was about 154,53 and $117 \mathrm{~W} \mathrm{~m}^{-2}$, on 1-3 December, respectively. On 3 December, the heat flux showed a dramatically decrease, e.g., from 117 to $53 \mathrm{~W} \mathrm{~m}^{-2}$ in $1 \mathrm{~h}$ (11:00-12:00 LST), which aggravated the negative effect on pollutant diffusion (corresponding to the CS). There was a thick temperature inversion close to the surface that lasted till the afternoon on 4 December, as described in the last section, which resulted in the downward heat transfer $(H<0)$ to the urban surface in daytime. Gao et al. (2015) also found that large positive radiative forcing reduced the $H$ and LE by $5-16 \mathrm{~W} \mathrm{~m}^{-2}$ and $1-5 \mathrm{~W} \mathrm{~m}^{-2}$ during a severe fog-haze event over the NCP, by using WRF-Chem model simulations. By analyzing the measurements collected at a rural site (farmland) Gucheng in Hebei Province from 1 December 2016 to 31 January 2017 in winter, Liu et al. (2018) confirmed that the mean daily maximum $H$ was only $40 \mathrm{~W} \mathrm{~m}^{-2}$ on heavily polluted days (daily mean $\mathrm{PM}_{2.5}$ concentration $>150 \mu \mathrm{g} \mathrm{m}^{-3}$ ), but reached $90 \mathrm{~W} \mathrm{~m}^{-2}$ on clean days (daily mean $\mathrm{PM}_{2.5}$ concentration $<75 \mu \mathrm{g} \mathrm{m}^{-3}$ ). Model simulations have pointed out that the reduced sensible heat resulting from aerosol backscattering could lower the air temperature and suppress the growth of the ABL (Yu et al., 2002). In our case, the large reductions of $H$ on 2-4 December also imply that the high $\mathrm{PM}_{2.5}\left(\mathrm{PM}_{1}\right)$ concentrations from the nighttime till after sunrise may have suppressed the evolution of the UBL. Further and more detailed investigation into the development of the UBL was reported in the next section.

Mostly, during daytime, $G-Q_{\mathrm{F}}$ was the largest consuming term in the SEB, accounting for about $65 \%, 83 \%, 78 \%$ and $71 \%$ averaged in the afternoon hours (12:00-14:00 LST) on 1-4 December, respectively. Although changes in $Q_{\mathrm{F}}$ at the IAP site are unknown due to unavailable accurate energy consumption and traffic flow data, the $Q_{\mathrm{F}}$ term, an additional energy source, is always positive and can be assumed similarly during different days in a short term. Thus, the larger ratio of $G-Q_{\mathrm{F}}$ relative to $R_{\mathrm{n}}\left(\left(G-Q_{\mathrm{F}}\right) / R_{\mathrm{n}}\right)$ implies much 

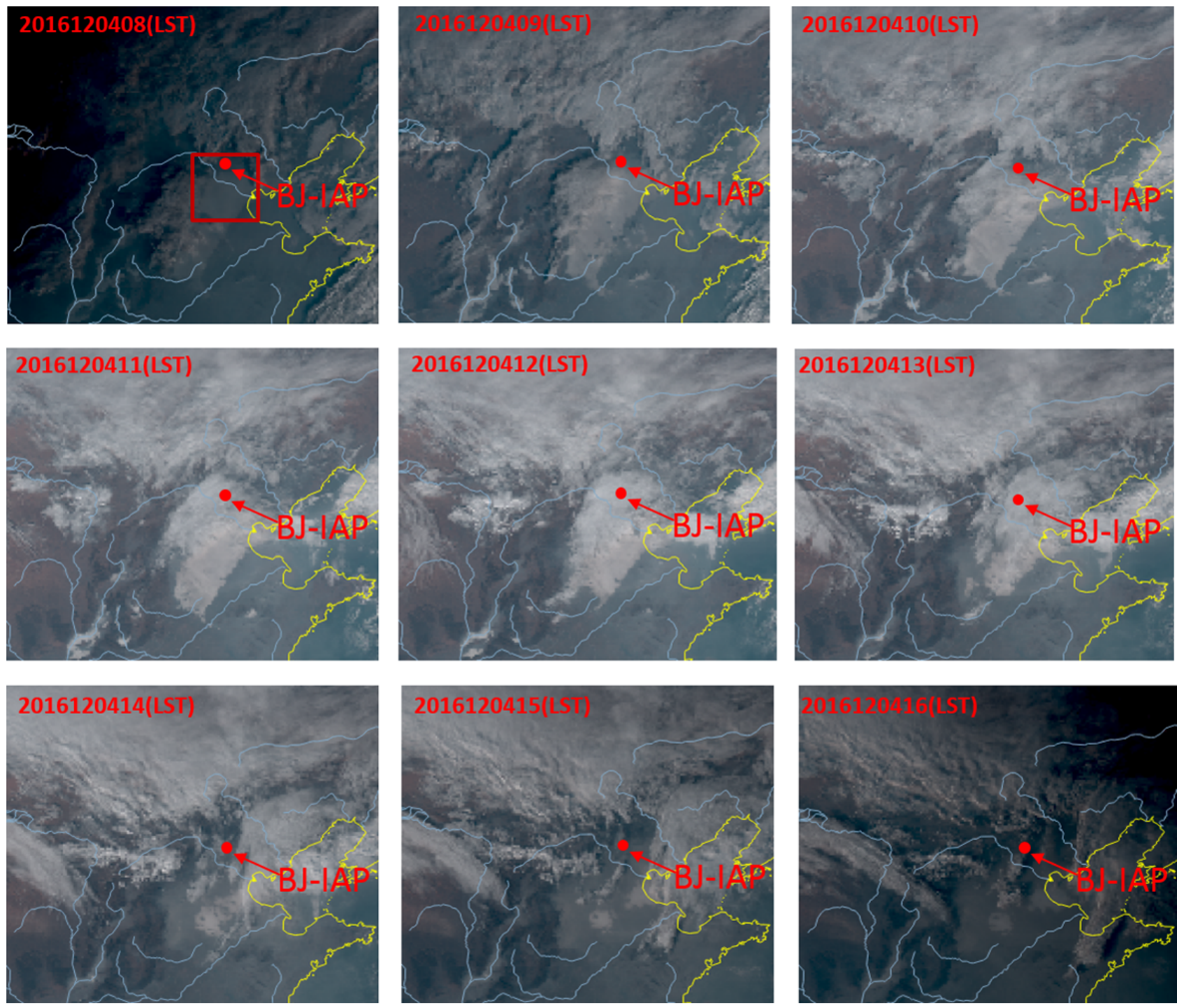

Figure 8. Hourly Himawari-8 geostationary meteorological satellite cloud images from 08:00 to 16:00 LST, 4 December, where the red point marks the location of the IAP station in Beijing, and the red square marks the mass of grey.

more heat is stored in the urban canopy, compared with other terms. Heat storage can be affected by different factors including atmospheric conditions (e.g., solar radiation, air temperature and wind speed) and urban characteristics (e.g., urban morphology, material properties and layout configuration) (Meehl and Tebaldi, 2004; Lindberg and Grimmond, 2011; Miralles et al., 2014; Sun et al., 2017). Urbanization results in land-cover change from vegetative to urban surfaces, and modifies the fractional coverage of urban. The fraction of impervious surfaces around the $325 \mathrm{~m}$ tower was investigated using an analytical footprint model and found to exceed $65 \%$ (Wang et al., 2014). Such a large fraction of impervious urban surfaces in Beijing leads to large urban heat capacity. During the early morning on 2 December, the air temperature near the surface (illustrated in Fig. 4) was lower than on other mornings (i.e., at around 04:00 LST, about $5{ }^{\circ} \mathrm{C}$ lower than on 1 December at $2 \mathrm{~m}$ level $\mathrm{ABG}$ ) and dropped to around zero, meaning a large amount of heat was lost from the urban volume. Then after sunrise, due to the high thermal conductivity of the concrete (about 65 times as large as the air), a considerable part of the $R_{\mathrm{n}}$ (maximum reaching $85 \%$ at 12:00 LST for $G-Q_{\mathrm{F}}$ ) was balanced by the heat storage in the urban fabric. Compared with 1 December, the larger heat storage with similar $R_{\mathrm{n}}$ (differing by less than $16 \mathrm{~W} \mathrm{~m}^{-2}$ ) on 2 December led to weaker heat flux, which was unfavorable to the diffusion of the pollutants (a slight increasing trend in $\mathrm{PM}_{2.5} / \mathrm{PM}_{1}$ from 09:00 LST to noon, Fig. 2). Specifically, under the conditions of early morning, much more solar heat is absorbed to warm the large urban fabric after sunrise. In addition, previous studies have demonstrated 

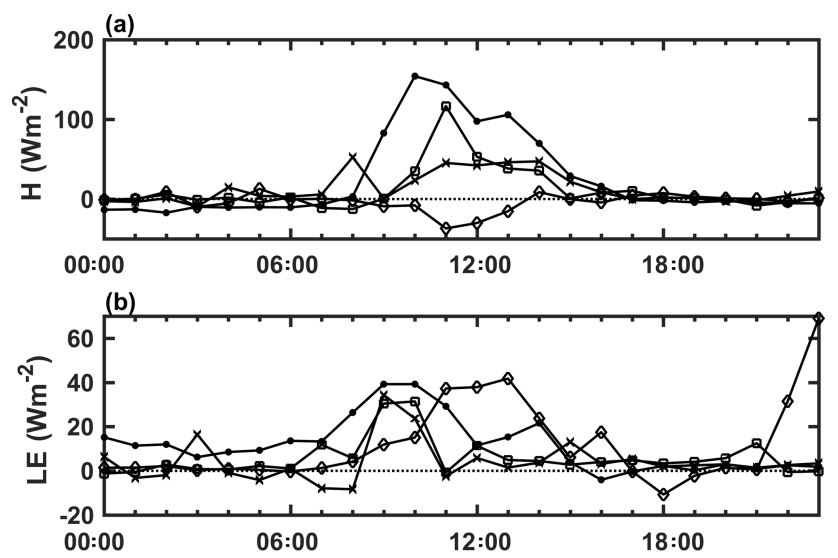

(c)

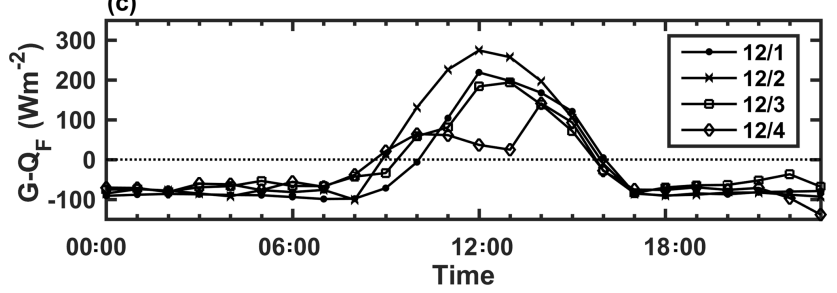

Figure 9. Diurnal cycle of (a) sensible heat flux, (b) latent heat flux and (c) heat storage minus anthropogenic heat (termed as $R_{\mathrm{n}}-$ $H-\mathrm{LE}$ ), observed at the $140 \mathrm{~m}$ level of the $325 \mathrm{~m}$ tower during 1-4 December 2016.

wind was a key determinant of changes in storage heat and the increasing amount of daytime heat storage in the urban canopy was strongly tied to lower wind speeds (Grimmond and Oke, 1999; Vautard et al., 2010; Sun et al., 2017). Thus, in this case, the weaker wind (Fig. 4c), associated with weak turbulent transport, contributed the larger heat storage ratios during polluted daytime, in particular on 2 December. Compared with the rural surface, Kotthaus and Grimmond (2014) reported the heat storage in urban surfaces led to delayed warming and cooling after sunrise and sunset, which resulted in the nocturnal stable conditions generally developing later (Barlow et al., 2015). In our study, generally, over the urban surface, compared with the clean daytime air, the polluted daytime air with calm wind conditions not only had reduced $R_{\mathrm{n}}$ but also a larger heat storage ratio, which contributed to weaker heat flux.

To improve our understanding of the role of the SEB in air pollution process, more work is needed, such as consideration of the uncertainty in eddy-covariance observations over complex heterogeneous urban surfaces and $Q_{\mathrm{F}} . Q_{\mathrm{F}}$ is a very important term of SEB in urban areas (Sailor, 2011; Chow et al., 2014), and this additional heat release will enhance $H$ and then increase the air temperature and BLH (Yu et al., 2014). Yang et al. (2018) found that incorporating anthropogenic heat emissions into the modeling system was effective in improving air quality predictions in Beijing. More specific studies on the impacts of the $Q_{\mathrm{F}}$ on the meteorology and air quality of the greater Beijing area can be made by urban-rural contrast with more observational data, or numerical models in further study.

\subsection{Development of the UBL}

The diurnal cycle of the ABL exerts strong control on the scalar concentrations of air pollutants (Oke et al., 2017). It is known that the ABL starts to grow after sunrise and deepens to a maximum value in midafternoon, then decreasing with the decreasing solar radiation reaching ground surface, during which the whole layer is convectively unstable and well mixed and is defined as CBL. After sunset, accompanied by diminishing turbulence, the boundary layer depth declines rapidly, and then the boundary layer becomes the NBL. Based on the general changes in BLH, the turbulent kinetic energy (TKE) at a certain depth or the amount of solar radiation, previous studies have proven that vertical mixing affects pollutant diffusion (Guinot et al., 2006; Sun et al., 2013; Guo et al., 2017). However, few have documented the diurnal circle of the intensity variation in vertical mixing in the UBL, on account of the limitation of instruments. Here, we took advantage of the Doppler lidar (superior spatial and temporal resolution) to quantify the values of the vertical mixing, described as vertical velocity variance $\sigma_{w}^{2}$ on clean and polluted days.

As presented in Fig. 10, it was found that the variance of $\sigma_{w}^{2}$ could characterize the development of the UBL. $\sigma_{w}^{2}$ became greater after sunrise (07:20 LST), then reached a maximum at about 14:00 LST, exhibiting an obvious trend of decline (from $\sigma_{w}^{2}>10^{-1}$ to $\sigma_{w}^{2}<10^{-2} \mathrm{~m} \mathrm{~s}^{-1}$ ) after sunset (16:50 LST). When the UBL developed into NBL, $\sigma_{w}^{2}$ was about $10^{-3} \mathrm{~m} \mathrm{~s}^{-1}$ at the $200-300 \mathrm{~m}$ levels till midnight and decreased to about $10^{-4} \mathrm{~m} \mathrm{~s}^{-1}$ after midnight until sunset. $\sigma_{w}^{2}$ was obviously lower and its vertical distribution shallower during daytime pollution episodes compared with the daytime clean episode, which is consistent with the results concluded by analysis of SEB. The diminished $R_{\mathrm{n}}$ and enhanced heat storage ratio during polluted daytime on 2-4 December resulted in the weak vertical mixing. On 4 December, the vertical mixing was extremely weak, ranging from $10^{-4}$ to $10^{-5}$, and there was barely any diurnal variation in $\sigma_{w}^{2}$ till 15:00 LST when the $\mathrm{PM}_{2.5}\left(\mathrm{PM}_{1}\right)$ had completely dissipated, which suggests the radiative cooling of aerosols and cloud was a major factor of influence in the UBL development by suppressing vertical mixing. Weak turbulence in this stagnating UBL could not break the deep temperature inversion (Fig. 5a), and such a shallow UBL seemed to act as an umbrella, blocking the entrainment with cold, clean air at the upper level, and solar radiation to the surface, and in return further suppressing the diffusion of pollutants, leading to not only the increasing $\mathrm{PM}_{2.5}\left(\mathrm{PM}_{1}\right)$ concentration during the $\mathrm{CS}$ but also much slower diffusion of $\mathrm{PM}_{1}$ at the surface than that at the $260 \mathrm{~m}$ level (Fig. 2). Accordingly, in our case study, the two-way feedback mechanism between air pollutants and the 


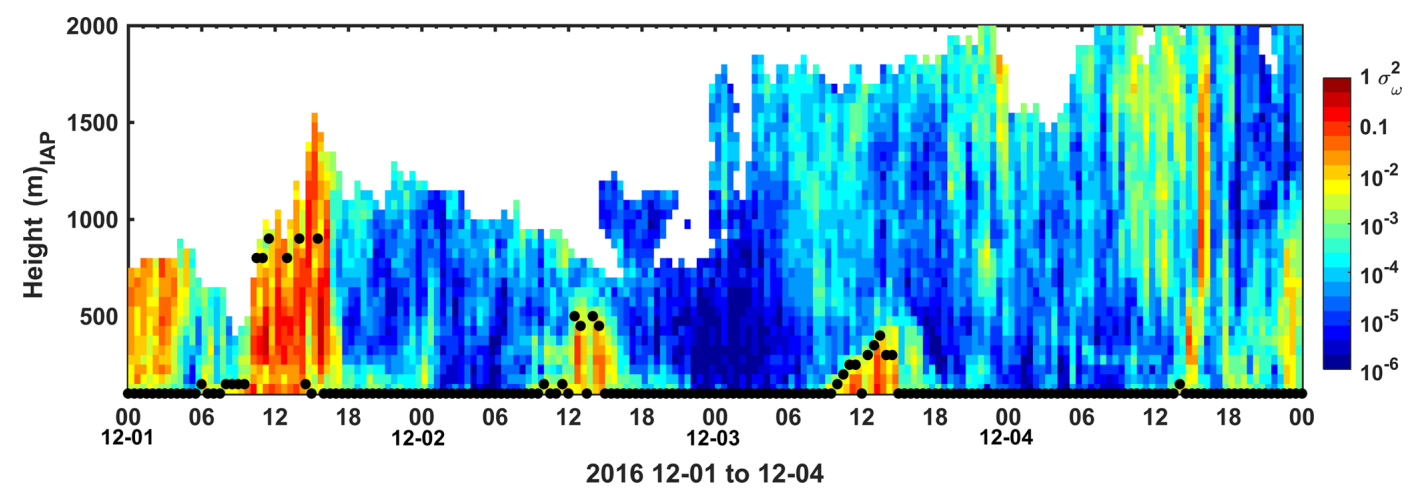

Figure 10. Velocity variance, $\sigma_{w}^{2}\left(\mathrm{~m}^{2} \mathrm{~s}^{-2}\right)$, calculated from the Doppler wind lidar data. Derived planetary boundary layer depths, based on the threshold method, are depicted as black dots.

UBL is strikingly responsible for the cumulative and dissipation stages of these pollution episodes.

Compared to 1 December, the vertical mixing was weaker till about $5 \mathrm{~h}$ after the sunrise on 2 December (CS). This weak evolution of the CBL was consistent with the weak sensible heat flux (Fig. 9). As discussed in Sect. 3.3, a large amount of the heat was trapped in the cold urban fabrics under calm wind conditions (Fig. 2), resulting in poor sensible heat flux after sunrise and weak vertical mixing on 2 December.

Additionally, the $\sigma_{w}^{2}$ mainly ranged from $10^{-6}$ to $10^{-5} \mathrm{~m} \mathrm{~s}^{-1}$ a.g.l. to the detectable observing height during nighttime from 22:00 LST, 2 December, till the early morning 05:00 LST before the CS on 3 December. This ultra-weak turbulence transport maintained a very shallow and stable NBL. Note that values of the $\mathrm{PM}_{1}$ concentration (Fig. 2) at the $260 \mathrm{~m}$ height of the $325 \mathrm{~m}$ tower changed slightly with time during the ultra-weak turbulence transport periods. Moreover, before the CS on 3 December, the aerosol lidar data (Fig. 11) showed that the gradient of the range-squaredcorrected signals (RSCS, calculated by $\left(\mathrm{RS}-\mathrm{RS}_{0}\right) r^{2}$ is applied to compensate for range-related attenuation from the atmosphere, where the lidar signal RS is corrected for the background noise contribution due to atmospheric skylight and electronic noise of the instrumentation used, the $\mathrm{RS}_{0}$ is the background signal and $r$ is the range between the lase source and the target) between the levels of 200-250 and 400-500 ma.g.l. was larger than the other levels from 18:00 LST (after sunset) 2 December to 05:00 LST (before sunrise) 3 December. As we know, both aerosols and water vapor affect the signals of the lidar. The larger RSCS at the time mentioned above, in our case, must not only have been because of the water vapor but also aerosol concentrations, consistent with the larger $\mathrm{PM}_{1}$ concentration at the $260 \mathrm{~m}$ level (more than $100 \mu \mathrm{g} \mathrm{m}^{-3}$ ). Similarly, the larger RSCS between the levels of 200-250 and 400-500 ma.g.l. illustrated these levels were accumulated with high levels of pollutants and the vertical distribution of pollutants was inhomogeneous, all of which implies that the $260 \mathrm{~m}$ level may have been in the residual layer. The pollutants in the resid- ual layer are known to play an important role in the diurnal changes of pollutants at the surface (Hastie et al., 1993; Berkowitz et al., 2000; Salmond and Mckendary, 2006). Sun et al. (2013) suggested that the high concentration of particles in the residual layer could reach the ground the following morning through convection, causing severe pollutant concentrations in Beijing. In the Tianjin area, Han et al. (2018) also found that a pollution layer was present at the altitude of $1000 \mathrm{~m}$ in the early morning on 16 December 2016, where the aerosols in the higher layers were transmitted to the ground by downward flow before the formation of heavy pollution. Actually, many studies have focused on this mechanism of pollutant vertical mixing in a stable NBL from the micrometeorology perspective. Turbulence in a very stable NBL is typically intermittent and generated by mechanical shear associated with changes in wind velocity with height (Mahrt et al., 1998), referred to as upside-down turbulence in an upside-down boundary structure, compared to the convective daytime case (Mahrt, 1999; Mahrt and Vickers, 2002). This upside-down structure is characterized by TKE (or $\sigma_{w}^{2}$ ), turbulent fluxes increasing with height, and negative transportation of TKE or velocity variances (Banta et al., 2006). As shown in Fig. 10, the $\sigma_{w}^{2}$ became larger at lower levels from 05:00 LST, 3 December, and then the largest values of $\sigma_{w}^{2}$ existed at 500-600 m, along with the corresponding $|\Delta U|$ shown in Fig. 6b. This turbulence could transport the pollutants accumulated in the residual layer downward to the lower levels, and contributed to the later CS of the pollution. Halios and Barlow (2018) also suggested that shear production dominates in the upper half of the UBL and could therefore not be neglected, even in cases with low wind. Consequently, the intermittent turbulence generated by the wind shear above a stable UBL plays an important role in the vertical spreading of pollutants.

As a key variable describing the structure of the UBL, the urban BLH estimated using the threshold method $\left(\sigma_{w}^{2}>\right.$ $0.1 \mathrm{~m}^{2} \mathrm{~s}^{-2}$ ) from the Doppler lidar data is also shown in Fig. 10. For the CBL, the diurnal variations in CBL height were not described well by the threshold method for these 


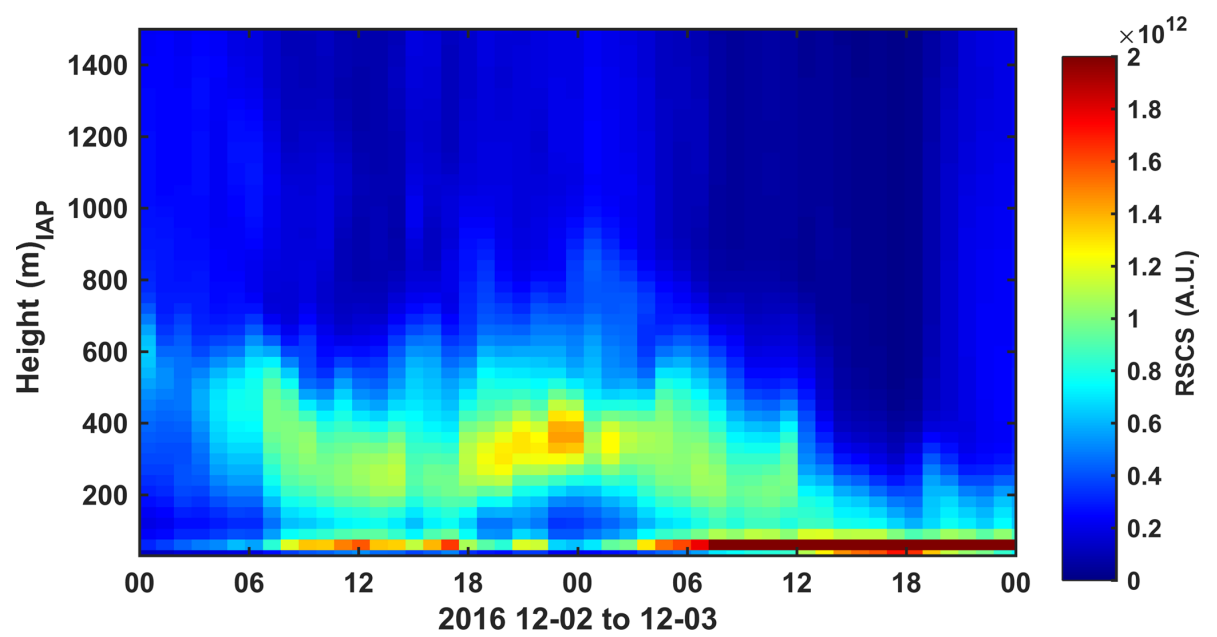

Figure 11. Evolution of the lidar range-squared-corrected signal (RSCS) at $532 \mathrm{~nm}$ from 12:00 LST, 2 December, to 12:00 LST, 3 December 2016. The color scale indicates the intensity of the RSCS, and warm colors represent stronger light scattering.

$4 \mathrm{~d}$, and especially on 4 December for the weak turbulence on the polluted day. Eventually, this empirical method was derived using data in autumn or summer, during which the vertical turbulence is much greater than in the winter. In our study, the criterion $\sigma_{w}^{2}>0.1 \mathrm{~m}^{2} \mathrm{~s}^{-2}$ was not applicable because of weak vertical turbulence transport $\left(\sigma_{w}^{2}<0.1 \mathrm{~m}^{2} \mathrm{~s}^{-2}\right)$ at certain times of the day. The threshold method was also invalid in the NBL during this study period. This may be because of the weak vertical turbulence or smaller height of the NBL falling below the observable height $(100 \mathrm{~m})$. Using Windcube 100 data during summer in Beijing, Huang et al. (2017) also pointed out that this method was reasonable for estimating the CBL depth, while it failed to determine the planetary boundary layer depths for late in the night. Subsequently, they defined the NBL top as the height at which the vertical velocity variance decreases to $10 \%$ of its near-surface maximum minus a background variance. However, this new method for the depth of the NBL also failed in our studied period (figure omitted). This is because the NBL in winter is mostly steady, which does not satisfy the near-neutral assumption for the method developed by Huang et al. (2017). Additionally, the NBL has been a major problem for meteorologists for a long time, especially over polluted urban canopies, which make the problem far more complex. Therefore, further investigation of this method should be made in future.

Miao et al. (2018) pointed out that the BLH of a fully developed CBL was clearly anticorrelated with the daily $\mathrm{PM}_{2.5}$ concentration, implying that the change in the BLH in the afternoon plays an important role in pollution levels, which is similar to our present conclusion. Furthermore, the mixing heights of the fully coupled CBL for 1-4 December were about 900,500 and $400 \mathrm{~m}$, respectively. Due to the weaker mixing intensity on 4 December, it is difficult to capture specific values of the BLH. As shown in Fig. 2, the max- imum daily $\mathrm{PM}_{2.5}\left(\mathrm{PM}_{1}\right)$ concentrations increased day by day from 1 to 3 December, indicating high pollutant concentration near the surface coincides with a shallow CBL. Petäjä et al. (2016) reported that aerosol-boundary layer feedback remained moderate at fine PM concentrations lower than $200 \mu \mathrm{g} \mathrm{m}^{-3}$ in the Nanjing area, but became intensive at higher PM loadings, and the BLH decreased to half of the original height at particle mass concentrations slightly above $200 \mu \mathrm{g} \mathrm{m}^{-3}$. Similarly, particularly strong interactions were verified in the Beijing area when the $\mathrm{PM}_{2.5}$ mass concentration was larger than $150-200 \mu \mathrm{g} \mathrm{m}^{-3}$ (Luan et al., 2018). In our investigation, the BLH was reduced by about $44 \%$ on 2 December with the low $\mathrm{PM}_{2.5}\left(\mathrm{PM}_{1}\right)$ concentration 46 (48) $\mu \mathrm{g} \mathrm{m}^{-3}$ and only a $5 \%$ attenuation of $R_{\mathrm{n}}$. Additionally, for the $\mathrm{PM}_{2.5}\left(\mathrm{PM}_{1}\right)$ concentration of $180(150) \mu \mathrm{g} \mathrm{m}{ }^{-3}$ on 3 December, a $56 \%$ reduction of the BLH was found with a $27 \%$ attenuation of $R_{\mathrm{n}}$. Therefore, in addition to the $R_{\mathrm{n}}$ term, it is important to note that the heat storage term in the SEB also makes a significant contribution to the reduction of BLH (details discussed in Sect. 3.3). In particular, over the megacity Beijing with a large fraction of impervious surface, heat storage accounts for a great amount of net radiation and its ratio increases with decreasing wind speed, which should be excluded from the quantitative analysis of the impact of aerosol pollutants on the UBL. Otherwise, the response degree of the UBL to aerosol pollutants would be overestimated, owing to the polluted days mostly accompanied by weak wind in Beijing.

Note that the BLH decreased significantly from 1 December to 2 December, while the $\mathrm{PM}_{2.5} / \mathrm{PM}_{1}$ concentration increased only a little, which implied that the reduced BLH must be a negative factor, yet not the only one, in the dispersion of pollutants. As mentioned in the introduction part, heavy pollution in Beijing is also highly related to high relative humidity $(\mathrm{RH})$, which is positive for the rapid forma- 


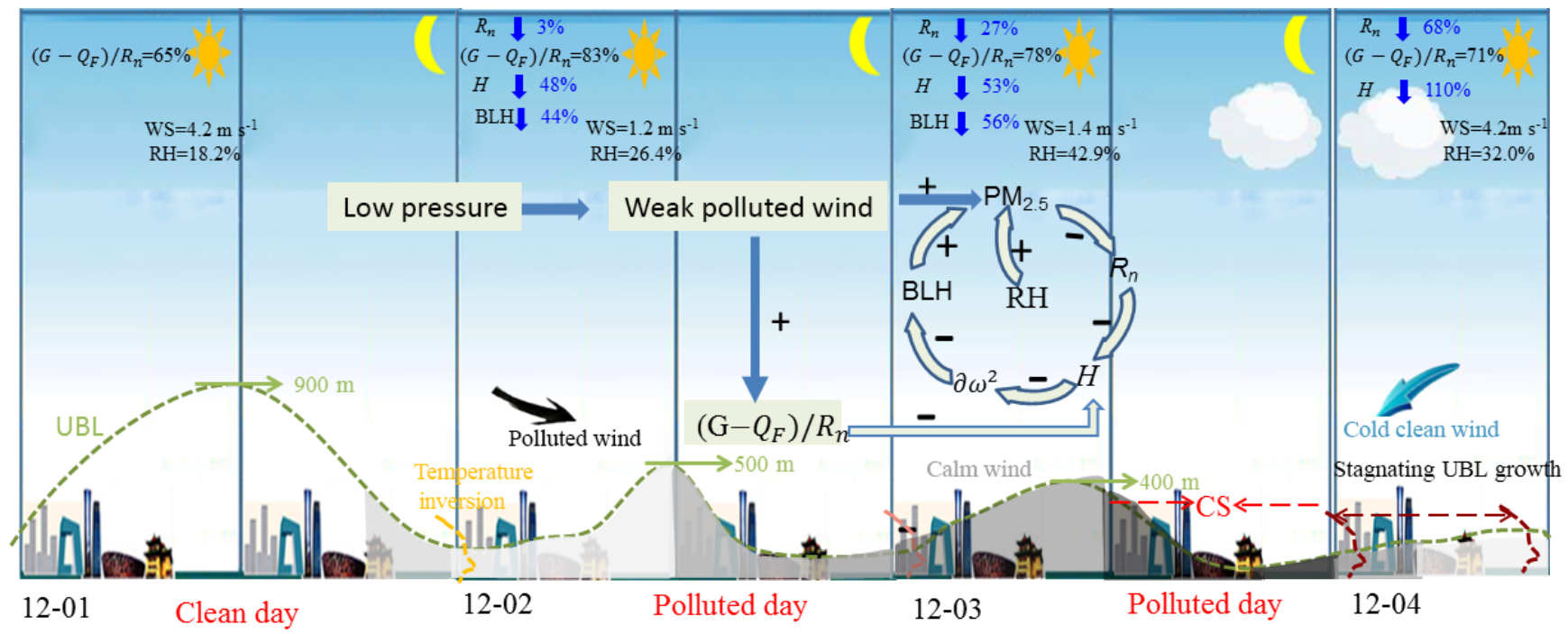

$R_{n}$ : net radiation $H$ : sensible heat flux $G$ : heat storage $Q_{F}$ : anthropogenic heat WS: wind speed RH: relativehumidity BLH: boundary layer height UBL: urban boundary layer $\partial \omega^{2}$ : vertical velocity variance

Figure 12. Schematic diagrams of the roles of synoptic conditions, surface energy budget in the development of UBL, and the two-way feedback between UBL structure and accumulation of $\mathrm{PM}_{2.5}$ during 1-4 December 2016; the values of meteorological elements are averaged for afternoon hours (12:00-14:00 LST).

tion of secondary aerosol. On 3 December, during the period after sunrise before the CS, with weak winds, appreciable near-surface moisture accumulation appeared with $\mathrm{RH}$ over $60 \%$ (Fig. 4c, a), while the RH was about $40 \%$ after sunrise on 2 December. Based on previous studies (Tie et al., 2017; Zhong et al., 2019), such enhanced moisture on 3 December would reduce direct radiation through accelerating liquid-phase and heterogeneous reactions to produce more secondary aerosols and enhancing aerosol hygroscopic growth to increase aerosol particle size and mass (Kuang et al., 2016), which would backscatter more solar radiation to space. Thus, the lower RH on 2 December was negative to the formation of secondary aerosol, resulting in the lower $\mathrm{PM}_{2.5} / \mathrm{PM}_{1}$ concentration on 2 December than on 3 December. Moreover, the sustained stagnant conditions on 2 December contributed to a certain degree of the $\mathrm{PM}_{2.5} / \mathrm{PM}_{1}$ concentration before CS, which was one of the preconditions for the rapid formation of CS.

In general, the main impacts of synoptic conditions (pressure, wind, temperature, relative humidity, etc.) and surface energy balance on the UBL evolution, and then the interactions between the aerosol pollutants and UBL structure, can be summarized by a schematic diagram in the present study (Fig. 12), providing a critical reference for air pollution forecast and assessment in Beijing.

\section{Conclusion}

Using data from the $325 \mathrm{~m}$ meteorological tower in Beijing and two nearby lidars, we investigated the characteristics of UBL structure during 1-4 December 2016 in Beijing and examined the interaction between the structure of the UBL and the air pollution during three pollution episodes, especially the rapid CS during which the $\mathrm{PM}_{2.5}$ concentration rose from about 100 to $500 \mu \mathrm{g} \mathrm{m}^{-3}$ in $12 \mathrm{~h}$. The main conclusions can be summarized as follows.

1. During this $4 \mathrm{~d}$ study period, the air pollution gradually worsened on a day-by-day basis, with deceasing surface air pressure. In particular, the large-scale circulation with a saddled pressure field was highly unfavorable for the dispersion of pollutants on 3 December during the CS. The RH was larger than $40 \%$ during the heavy pollution episodes, and the vertical distribution of RH showed a remarkably inhomogeneous pattern during the peak period of the CS with the deep RH $(>80 \%)$ at the 47-240 $\mathrm{m}$ levels and heavy surface $\mathrm{PM}_{2.5} / \mathrm{PM}_{1}$ concentration (about $500 \mu \mathrm{g} \mathrm{m}^{-3} / 400 \mu \mathrm{g} \mathrm{m}^{-3}$ ) in the early morning on 4 December. Temperature inversion $(\Delta \theta>$ 0 ) occurred during all three nights. For the first pollution episode during nighttime on 1-2 December, a southern neutral LLJ was found at the 200-1000 m levels after sunset till midnight over Beijing, which transported the pollutants from the south of Beijing by advection. For the second episode during nighttime on 2-3 December, weak southerly wind $\left(<3 \mathrm{~m} \mathrm{~s}^{-1}\right)$ dominated below the $600 \mathrm{~m}$ level, with small vertical gradients, due to the 
saddle-type pressure-field background. Meanwhile, for CS on 3 December, there was a very deep and weak wind layer, which extended to about the $1100 \mathrm{~m}$ level till 22:00 LST, 3 December, when the accumulated $\mathrm{PM}_{2.5}$ concentration was larger than $400 \mu \mathrm{g} \mathrm{m}^{-3}$ at the surface.

2. Compared with the DSR during the daytime clean episode on 1 December, the attenuation ratio of the DSR was about $5 \%, 24 \%$ and $63 \%$, in the afternoon hours (12:00-14:00 LST) on 2-4 December, which mainly caused a $3 \%, 27 \%$ and $68 \%$ reduction of the $R_{\mathrm{n}}$. The large attenuation of solar radiation on 4 December resulted from the cloud caused by the large aerosol loading with high RH on 3 December, possibly supporting plentiful CNN for the formation of cloud. Generally, the latent heat exchange term was very low during these $4 \mathrm{~d}$ over the urban canopy in Beijing, and the dominant term was mostly the heat storage minus anthropogenic heat, calculated as $R_{\mathrm{n}}-H-\mathrm{LE}$, during daytime, which accounted for about $65 \%, 83 \%, 78 \%$ and $71 \%$ of $R_{\mathrm{n}}$ (averaged 1200-14:00 LST) on 1-4 December. We also found that lower $H$ appeared on the polluted days than on the clean days, which was partly caused by the large consuming term of the heat storage in the urban fabric with calm wind conditions.

3. In the CBL, the diurnal circle of lidar-based $\sigma_{w}^{2}$ agreed with the variation in the diurnal cycle of $H$ estimated by the eddy-covariance method at the $140 \mathrm{~m}$ level of the $325 \mathrm{~m}$ tower, showing that vertical mixing was obviously weakened on polluted days. Compared to the clean day, the evolution of the UBL was delayed by about $5 \mathrm{~h}$ after sunrise (about 07:20 LST) on 4 December because of the long-term $(>12 \mathrm{~h}$ ) existence of temperature inversion resulting from the effects of both aerosols and clouds. This stagnating UBL seemed to act like an umbrella, suppressing the diffusion of $\mathrm{PM}_{1}$ at the surface, which was cleaned at about 15:00 LST, while the $\mathrm{PM}_{1}$ at the $260 \mathrm{~m}$ level was driven away by the strong clean northerly wind flow at about 07:00 LST. Therefore, this two-way feedback mechanism between air pollutants and the UBL was strikingly responsible for the cumulative and dissipation stages of this pollution event in our case. Additionally, the intermittent turbulence generated by the wind shear above the stable NBL in the early morning on 3 December may have contributed to the CS through the downward transport of pollutants from the residual layer. Compared to $1 \mathrm{De}-$ cember the reduction of the maximum BLH was $44 \%$ on 2 December and $56 \%$ on 3 December, whereas the BLH on 4 December was unobtainable due to the stagnating UBL growth.

Data availability. Data used in this study are available from the corresponding author upon request.
Author contributions. LW and GZ determined the goal of this study. LW carried it out, analyzed the data and prepared the paper with contributions from all co-authors. JL, MH and SF helped to process the three-dimensional sonic anemometer, Doppler and dualwavelength depolarization lidar original records. SM provided radiation observations. HZ provided Doppler data. YS provided $\mathrm{PM}_{1}$ data. TY provided dual-wavelength depolarization lidar data. LW wrote the first draft of the paper. All authors contributed to the improvement of this paper and approved the final version of the paper.

Competing interests. The authors declare that they have no conflict of interest.

Acknowledgements. This work was funded by the National Key Research and Development Program of the Ministry of Science and Technology of China (2016YFC0203304 and 2017YFC0209601) and the open funding of State Key Laboratory of Loess and Quaternary Geology (SKLLQG1842). We also thank the three anonymous reviewers for their valuable comments and suggestions.

Financial support. This research has been supported by the National Key Research and Development Program of Ministry of Science and Technology of China (grant nos. 2016YFC0203304 and 2017YFC0209601) and the open funding of the State Key Laboratory of Loess and Quaternary Geology (SKLLQG1842).

Review statement. This paper was edited by Stefano Galmarini and reviewed by three anonymous referees.

\section{References}

Banta, R. M., Pichugina, Y. L., and Brewer, W. A.: Turbulent velocity-variance profiles in the stable boundary layer generated by a nocturnal low-level Jet, J. Atmos. Sci., 63, 2700-2719, https://doi.org/10.1175/JAS3776.1, 2006.

Barbaro, E., Vilà-Guerau de Arellano, J., Krol, M. C., and Holtslag, A. A. M.: Impacts of aerosol shortwave radiation absorption on the dynamics of an idealized convective atmospheric boundary layer, Bound.-Lay. Meteorol., 148, 31-49, https://doi.org/10.1007/s10546-013-9800-7, 2013.

Barlage, M., Miao, S. G., and Chen, F.: Impact of physics parameterizations on high-resolution weather prediction over two Chinese megacities, J. Geophys. Res., 121, 4487-4498, https://doi.org/10.1002/2015JD024450, 2016.

Barlow, J. F., Halios, C. H., Lane, S. E., and Wood, C. R.: Observations of urban boundary layer structure during a strong urban heat island event, Environ. Fluid Mech., 15, 373-398, https://doi.org/10.1007/s10652-014-9335-6, 2015.

Berkowitz, C. M., Fast, J. D., and Easter, R. C.: Boundary layer vertical exchange processes and the mass budget of ozone: Observations and model results, J. Geophys. Res., 105, 14789-14805, https://doi.org/10.1029/2000jd900026, 2000. 
Che, H. C., Zhang, X. Y., Wang, Y. Q., Zhang, L., Shen, X. J., Zhang, Y. M., Ma, Q. L., Sun, J. Y., Zhang, Y. W., and Wang, T. T.: Characterization and parameterization of aerosol cloud condensation nuclei activation under different pollution conditions, Sci. Rep., 6, 24497, https://doi.org/10.1038/srep24497, 2016.

Che, H., Xia, X., Zhu, J., Li, Z., Dubovik, O., Holben, B., Goloub, P., Chen, H., Estelles, V., Cuevas-Agulló, E., Blarel, L., Wang, H., Zhao, H., Zhang, X., Wang, Y., Sun, J., Tao, R., Zhang, X., and Shi, G.: Column aerosol optical properties and aerosol radiative forcing during a serious haze-fog month over North China Plain in 2013 based on ground-based sunphotometer measurements, Atmos. Chem. Phys., 14, 2125-2138, https://doi.org/10.5194/acp-14-2125-2014, 2014.

Chen, Y., An, J. L., Sun, Y. L., Wang, X. Q., Qu, Y., Zhang, J. W., Wang, Z. F., and Duan, J.: Nocturnal low-level winds and their impacts on particulate matter over the Beijing area, Adv. Atmos. Sci., 35, 1455-1468, https://doi.org/10.1007/s00376-018-80229, 2018.

Chen, Y., An, J. L., Wang, X. Q., Sun, Y. L., Wang, Z. F., and Duan, J.: Observation of wind shear during evening transition and an estimation of submicron aerosol concentrations in Beijing using a Doppler wind lidar, J. Meteor. Res., 31, 350-362, https://doi.org/10.1007/s13351-017-6036-3, 2017.

Cheng, X. L., Liu, X. M., Liu, Y. J., and Hu, F.: Characteristics of $\mathrm{CO}_{2}$ concentration and flux in the Beijing urban area, J. Geophys. Res., 1785-1801, https://doi.org/10.1002/2017jd027409, 2018.

Chow, W. T. L., Salamanca, F. P., Georgescu, M., Mahalov, A., Milne, J. M., and Ruddell, B. L.: Amultimethod and multi-scale approach for estimating city-wide anthropogenic heat fluxes, Atmos. Environ. 99, 64-76, https://doi.org/10.1016/j.atmosenv.2014.09.053,2014.

Dickerson, R. R.: The Impact of Aerosols on Solar Ultraviolet Radiation and Photochemical Smog, Science, 278, 827-830, https://doi.org/10.1126/science.278.5339.827, 1997.

Ding, A. J., Huang, X., Nie, W., Sun, J. N., Kerminen, V. M., Petäjä, T., Su, H., Cheng, Y. F., Yang, X. Q., Wang, M. H., Chi, X. G., Wang, J. P., Virkkula, A., Guo, W. D., Yuan, J., Wang, S. Y., Zhang, R. J., Wu, Y. F., Song, Y., Zhu, T., Zilitinkevich, S., Kulmala, M., and Fu, C. B.: Enhanced haze pollution by black carbon in megacities in China, Geophys. Res. Lett., 43, 2873-2879, https://doi.org/10.1002/2016g1067745, 2016.

Emeis, S., Münkel, C., Vogt, S., Müller, W. J., and Schäfer, K.: Atmospheric boundary-layer structure from simultaneous SODAR, RASS, and ceilometer measurements, Atmos. Environ., 38, 273286, https://doi.org/10.1016/j.atmosenv.2003.09.054, 2004.

Flamant, C., Pelon, J., Flamant, P. H., and Durand, P.: Lidar determination of the entrainment zone thickness at the top of the unstable marine atmospheric boundary layer, Bound.-Lay. Meteorol., 83, 247-284, 1997.

Gao, Y., Zhang, M., Liu, Z., Wang, L., Wang, P., Xia, X., Tao, M., and Zhu, L.: Modeling the feedback between aerosol and meteorological variables in the atmospheric boundary layer during a severe fog-haze event over the North China Plain, Atmos. Chem. Phys., 15, 4279-4295, https://doi.org/10.5194/acp15-4279-2015, 2015.

Georgoulias, A. K., Papanastasiou, D. K., Melas, D., Amiridis, V., and Alexandri, G.: Statistical analysis of boundary layer heights in a suburban environment, Meteorol. Atmos. Phys., 104, 103111, https://doi.org/10.1007/s00703-009-0021-z, 2009.

Grimmond C. S. B. and Oke T. R.: Aerodynamic properties of urban areas derived, from analysis of surface form, J. Appl. Meteorol., 38 1262-1292, https://doi.org/10.1175/1520-0450, 1999.

Guinot, B., Roger, J. C., Cachier, H., Wang, P. C., Bai, J. H., and Yu, T.: Impact of vertical atmospheric structure on Beijing aerosol distribution, Atmos. Environ., 40, 5167-5180, https://doi.org/10.1016/j.atmosenv.2006.03.051, 2006.

Gunthe, S. S., Rose, D., Su, H., Garland, R. M., Achtert, P., Nowak, A., Wiedensohler, A., Kuwata, M., Takegawa, N., Kondo, Y., Hu, M., Shao, M., Zhu, T., Andreae, M. O., and Pöschl, U.: Cloud condensation nuclei $(\mathrm{CCN})$ from fresh and aged air pollution in the megacity region of Beijing, Atmos. Chem. Phys., 11, 1102311039, https://doi.org/10.5194/acp-11-11023-2011, 2011.

Guo, J. P., Xia, F., Zhang, Y., Liu, H., Li, J., Lou, M. Y., He, J., Yan, Y., Wang, F., Min, M., and Zhai, P. M.: Impact of diurnal variability and meteorological factors on the $\mathrm{PM}_{2.5}-\mathrm{AOD}$ relationship: Implications for $\mathrm{PM}_{2.5}$ remote sensing, Environ. Pollut., 221, 94-104, https://doi.org/10.1016/j.envpol.2016.11.043, 2017.

Halios, C. H. and Barlow, J. F.: Observations of the morning development of the urban boundary layer over London, UK, taken during the ACTUAL project, Bound.-Lay. Meteorol., 166, 395422, https://doi.org/10.1007/s10546-017-0300-z, 2018.

Haman, C. L., Lefer, B., and Morris, G. A.: Seasonal variability in the diurnal evolution of the boundary layer in a nearcoastal urban environment, J. Atmos. Ocean. Tech., 29, 697-710, https://doi.org/10.1175/jtech-d-11-00114.1, 2012.

Han, S. Q., Bian, H., Tie, X. X., Xie, Y. Y., Sun, M. L., and Liu, A. X.: Impact of nocturnal planetary boundary layer on urban air pollutants: measurements from a $250 \mathrm{~m}$ tower over Tianjin, China, J. Hazard Mater., 162, 264-269, https://doi.org/10.1016/j.jhazmat.2008.05.056, 2009.

Han, S. Q., Hao, T. Y., Zhang, Y. F., Liu, J. L., Li, P. Y., Cai, Z. Y., Zhang, M., Wang, Q. L., and Zhang, H.: Vertical observation and analysis on rapid formation and evolutionary mechanisms of a prolonged haze episode over central-eastern China, Sci. Total Environ., 616-617, 135-146, https://doi.org/10.1016/j.scitotenv.2017.10.278, 2018.

Hastie, D. R., Shepson, P. B., Sharma, S., and Schiff, H. I.: The influence of the nocturnal boundary layer on secondary trace species in the atmosphere at Dorset, Ontario, Atmos. Environ., 27, 533-541, https://doi.org/10.1016/0960-1686(93)90210$\mathrm{P}, 1993$.

Holmes, H. A., Sriramasamudram, J. K., Pardyjak, E. R., and Whiteman, C. D.: Turbulent fluxes and pollutant mixing during wintertime air pollution episodes in complex terrain, Environ. Sci. Technol., 49, 13206-13214, https://doi.org/10.1021/acs.est.5b02616, 2015.

Hu, X. M., Klein, P. M., Xue, M., Zhang, F. Q., Doughty, D. C., Forkel, R., Joseph, E., and Fuentes, J. D.: Impact of the vertical mixing induced by low-level jets on boundary layer ozone concentration, Atmos. Environ., 70, 123-130, https://doi.org/10.1016/j.atmosenv.2012.12.046, 2013.

Hu, X. M., Ma, Z. Q., Lin, W. L., Zhang, H. L., Hu, J. L., Wang, Y., Xu, X. B., Fuentes, J. D., and Xue, M.: Impact of the Loess Plateau on the atmospheric boundary layer structure and air quality in the North China Plain: a case study, Sci. Total Environ., 
499, 228-237, https://doi.org/10.1016/j.scitotenv.2014.08.053, 2014.

Huang, M., Gao, Z. Q., Miao, S. G., Chen, F., LeMone, M. A., Li, J., Hu, F., and Wang, L. L.: Estimate of boundarylayer depth over Beijing, China, using Doppler Lidar data during SURF-2015, Bound.-Lay. Meteorol., 162, 503-522, https://doi.org/10.1007/s10546-016-0205-2, 2017.

Kotthaus, S. and Grimmond, C. S. B.: Energy exchange in a dense urban environment - Part I: Temporal variability of longterm observations in central London, Urban Clim., 10, 261-280, https://doi.org/10.1016/j.uclim.2013.10.002, 2014.

Kuang, Y., Zhao, C. S., Tao, J. C., Bian, Y. X., and Ma, N.: Impact of aerosol hygroscopic growth on the direct aerosol radiative effect in summer on North China Plain, Atmos. Environ., 147, 224233, https://doi.org/10.1016/j.atmosenv.2016.10.013, 2016.

Li, J., Sun, J., Zhou, M., Cheng, Z., Li, Q., Cao, X., and Zhang, J.: Observational analyses of dramatic developments of a severe air pollution event in the Beijing area, Atmos. Chem. Phys., 18, 3919-3935, https://doi.org/10.5194/acp-18-3919-2018, 2018.

Li, X., Zhang, Q., Zhang, Y., Zhang, L., Wang, Y. X., Zhang, Q. Q., Li, M., Zheng, Y. X., Geng, G. N., Wallington, T. J., Han, W. J., Shen, W., and He, K. B.: Attribution of $\mathrm{PM}_{2.5}$ exposure in Beijing-Tianjin-Hebei region to emissions: implication to control strategies, Sci. Bull., 62, 957-964, https://doi.org/10.1016/j.scib.2017.06.005, 2017.

Li, Z. Q., Guo, J. P., Ding, A. J., Liao, H., Liu, J. J., Sun, Y. L., Wang, T. J., Xue, H. W., Zhang, H. S., and Zhu, B.: Aerosol and boundary-layer interactions and impact on air quality, Natl. Sci. Rev., 4, 810-833, https://doi.org/10.1093/nsr/nwx117, 2017.

Lindberg F. and Grimmond C. S. B.: The influence of vegetation and building morphology on shadow patterns and mean radiant temperatures in urban areas: model development and evaluation, Theor. Appl. Climatol. 105, 311-323, https://doi.org/10.1007/s00704-010-0382-8, 2011.

Liu, C. W., Gao, Z. Q., Li, Y. B., Gao, C. Y., Su, Z. B., and Zhang, X. Y.: Surface energy budget observed at a winter wheat field site in the north China plain during a fog-haze event, Bound.-Lay. Meteorol., 170, 489, https://doi.org/10.1007/s10546-018-0407$\mathrm{x}, 2018$.

Liu, J. K., Gao, Z. Q., Wang, L. L., Li, Y. B., and Gao, C. Y.: The impact of urbanization on wind speed and surface aerodynamic characteristics in Beijing during 1991-2011, Meteorol. Atmos. Phys., 130, 311-324, https://doi.org/10.1007/s00703-017-05198, 2017.

Liu, S. H., Liu, Z. X., Li, J., Wang, Y. C., Ma, Y. J., Sheng, L., Liu, H. P., Liang, F. M., Xin, G. J., and Wang, J. H.: Numerical simulation for the coupling effect of local atmospheric circulations over the area of Beijing, Tianjin and Hebei Province, Sci. China Ser. D, 52, 382-392, https://doi.org/10.1007/s11430-009-00302, 2009.

Luan, T., Guo, X., Guo, L., and Zhang, T.: Quantifying the relationship between $\mathrm{PM}_{2.5}$ concentration, visibility and planetary boundary layer height for long-lasting haze and fog-haze mixed events in Beijing, Atmos. Chem. Phys., 18, 203-225, https://doi.org/10.5194/acp-18-203-2018, 2018.

Mahrt, L.: Stratified atmospheric boundary layers, Bound.-Lay. Meteorol., 90, 375-396, 1999.
Mahrt, L. and Vickers, D.: Contrasting vertical structures of nocturnal boundarylayers, Bound.-Lay. Meteorol., 105, 351-363, https://doi.org/10.1023/A:1019964720989, 2002.

Mahrt, L., Sun, J. 1., Blumen, W., Delany, T., and Oncley, S.: Nocturnal boundary-layer regimes, Bound.-Lay. Meteorol., 88, 255278, https://doi.org/10.1023/A:1001171313493, 1998.

Meehl G. A. and Tebaldi C.: More intense, more frequent, and longer lasting heat waves in the 21st century, Science, 305, 994997, https://doi.org/10.1126/science.1098704, 2004.

Miao, S. G., Chen, F., Li, Q. C., and Fan, S. Y.: Impacts of urban processes and urbanization on summer precipitation: A case study of heavy rainfall in Beijing on 1 August 2006, J. Appl. Meteorol. Climatol., 50, 806-825, https://doi.org/10.1175/2010jamc2513.1, 2011.

Miao, S. G., Dou, J. X., Chen, F., Li, J., and Li, A. G.: Analysis of observations on the urban surface energy balance in Beijing, Sci. China Earth Sci., 55, 1881-1890, https://doi.org/10.1007/s11430-012-4411-6, 2012.

Miao, Y. C., Guo, J. P., Liu, S. H., Zhao, C., Li, X. L., Zhang, G., Wei, W., and Ma, Y. J.: Impacts of synoptic condition and planetary boundary layer structure on the trans-boundary aerosol transport from Beijing-TianjinHebei region to northeast China, Atmos. Environ. 181, 1-11, https://doi.org/10.1016/j.atmosenv.2018.03.005, 2018.

Miralles, D. G., Teuling, A. J., van Heerwaarden, C. C., and de Arellano, J. V.-G.: Mega-heatwave temperatures due to combined soil desiccation and atmospheric heat accumulation, Nat. Geosci., 7, 345-349, https://doi.org/10.1038/NGEO2141, 2014.

Oke, T. R., Mills, G., Christen, A., and Voogt, J. A.: Urban climates, Cambridge University Press, Cambridge, 157 pp., 2017.

Pearson, G., Davies, F., and Collier, C.: Remote sensing of the tropical rain forest boundary layer using pulsed Doppler lidar, Atmos. Chem. Phys., 10, 5891-5901, https://doi.org/10.5194/acp10-5891-2010, 2010.

Petäjä, T., Järvi, L., Kerminen, V. M., Ding, A. J., Sun, J. N., Nie, W., Kujansuu, J., Virkkula, A., Yang, X. Q., Fu, C. B., Zilitinkevich, S., and Kulmala, M.: Enhanced air pollution via aerosol-boundary layer feedback in China, Sci. Rep., 6, 18998, https://doi.org/10.1038/srep18998, 2016.

Ramanathan, V., Crutzen, P. J., Kiehl, J. T., and Rosenfeld, D.: Aerosols, climate, and the hydrological cycle, Science, 294, 2119-2126, https://doi.org/10.1126/science.1064034, 2001.

Sailor D. J.: A review ofmethods for estimating anthropogenic heat and moisture emissions in the urban environment, Int. J. Climatol., 31, 189-199, https://doi.org/10.1002/joc.2106, 2011.

Salmond, J. A. and McKendry, I. G.: A review of turbulence in the very stable nocturnal boundary layer and its implications for air quality, Prog. Phys. Geog., 29, 171-188, https://doi.org/10.1191/0309133305pp442ra, 2005.

Stone, R. S., Anderson, G. P., Shettle, E. P., Andrews, E., Loukachine, K., Dutton, E. G., Schaaf, C., and Roman, M. O.: Radiative impact of boreal smoke in the Arctic: Observed and modeled, J. Geophys. Res., 113, D14S16, https://doi.org/10.1029/2007jd009657, 2008.

Stull, R. B.: An Introduction to Boundary Layer Meteorology, Atmospheric Sciences Library, 8, 89 pp., 1988.

Sun, T., Kotthaus, S., Li, D., Ward, H. C., Gao, Z., Ni, G.-H., and Grimmond, C. S. B.: Attribution and mitigation of heat 
wave-induced urban heat storage change, Environ. Res. Lett., 12, 114007, https://doi.org/10.1088/1748-9326/aa922a, 2017.

Sun, Y. L., Jiang, Q., Wang, Z. F., Fu, P. Q., Li, J., Yang, T., and Yin, Y.: Investigation of the sources and evolution processes of severe haze pollution in Beijing in January 2013, J. Geophys. Res.-Atmos., 119, 4380-4398, https://doi.org/10.1002/2014JD021641, 2014.

Sun, Y. L., Wang, Z. F., Wild, O., Xu, W. Q., Chen, C., Fu, P. Q., Du, W., Zhou, L. B., Zhang, Q., Han, T. T., Wang, Q. Q., Pan, X. L., Zheng, H. T., Li, J., Guo, X. F., Liu, J. G., and Worsnop, D. R.: "APEC Blue": Secondary aerosol reductions from emission controls in Beijing, Sci. Rep., 6, 20668, https://doi.org/10.1038/srep20668, 2016.

Sun, Y., Song, T., Tang, G. Q., and Wang, Y. S.: The vertical distribution of $\mathrm{PM}_{2.5}$ and boundary-layer structure during summer haze in Beijing, Atmos. Environ., 74, 413-421, https://doi.org/10.1016/j.atmosenv.2013.03.011, 2013.

Tie, X., Huang, R.-J., Cao, J., Zhang, Q., Cheng, Y., Su, H., Chang, D., Pöschl, U., Hoffmann, T., Dusek, U., Li, G., Worsnop, D. R., and O'Dowd, C. D.: Severe Pollution in China Amplified by Atmospheric Moisture, Sci. Rep., 7, 15760, https://doi.org/10.1038/s41598-017-15909-1, 2017.

Tucker, S. C., Senff, C. J., Weickmann, A. M., Brewer, W. A., Banta, R. M., Sandberg, S. P., Law, D. C., and Hardesty, R. M.: Doppler lidar estimation of mixing height using turbulence, shear, and aerosol profiles, J. Atmos. Ocean. Tech., 26, 673-688, 2009.

Van Den Heever, S. C. and Cotton, W. R.: Urban aerosol impacts on downwind convective storms, J. Appl. Meteorol. Climatol., 46, 828-850, https://doi.org/10.1175/jam2492.1, 2007.

Vautard, R., Cattiaux, J., Yiou, P., Thépaut, J.-N., and Ciais, P.: Northern Hemisphere atmospheric stilling partly attributed to an increase in surface roughness, Nat. Geosci. 3, 756-761, 2010.

Wang, J. D., Xing, J., Wang, S. X., and Hao, J. M.: The pathway of aerosol direct effects impact on air quality: a case study by using process analysis, in: EGU General Assembly Conference Abstracts, 19, 8568, 2017.

Wang, L. L., Gao, Z. Q., Miao, S. G., Guo, X. F., Sun, T., Liu, M. F., and Li, D.: Contrasting characteristics of the surface energy balance between the urban and rural areas of Beijing, Adv. Atmos. Sci., 32, 505-514, https://doi.org/10.1007/s00376-0143222-4, 2015.

Wang, L. L., Li, D., Gao, Z. Q., Sun, T., Guo, X. F., and Bou-Zeid, E.: Turbulent transport of momentum and scalars above an urban canopy, Bound.-Lay. Meteorol., 150, 485-511, https://doi.org/10.1007/s10546-013-9877-z, 2014.

Wang, L. T., Wei, Z., Yang, J., Zhang, Y., Zhang, F. F., Su, J., Meng, C. C., and Zhang, Q.: The 2013 severe haze over southern Hebei, China: model evaluation, source apportionment, and policy implications, Atmos. Chem. Phys., 14, 3151-3173, https://doi.org/10.5194/acp-14-3151-2014, 2014.

Wang, L., Liu, J., Gao, Z., Li, Y., Huang, M., Fan, S., Zhang, X., Yang, Y., Miao, S., Zou, H., Sun, Y., Chen, Y., and Yang, T.: Observations of the atmospheric boundary layer structure over Beijing urban area during air pollution episodes, Atmos. Chem. Phys. Discuss., https://doi.org/10.5194/acp-2018-1184, in review, 2019.

Wang, X. R., Miao, S. G., Dou, J. X., Dong, P., and Wang, J. L.: Observation and analysis of the air pollution impacts on radiation balance of urban and suburb areas in Beijing, Chinese J.
Geophys., 59, 3996-4006, https://doi.org/10.6038/cjg20161106, 2016 (in Chinese).

Xia, X. G., Li, Z. Q., Holben, B., Wang, P. C., Eck, T., Chen, H. B., Cribb, M., and Zhao, Y. X.: Aerosol optical properties and radiative effects in the Yangtze Delta region of China, J. Geophys. Res., 112, D22S12, https://doi.org/10.1029/2007jd008859, 2007.

Yang, Y. J., Zheng, X. Y., Gao, Z. Q., Wang, H., Wang, T. J., Li, Y. B., Lau, G. N. C., and Yim, S. H. L.: Long-Term Trends of Persistent Synoptic Circulation Events in Planetary Boundary Layer and Their Relationships with Haze Pollution in Winter Half-Year over Eastern China, J. Geophys. Res., 123, 1099111007, https://doi.org/10.1029/2018JD028982, 2018.

Yang, T., Gbaguidi, A., Zhang, W., Wang, X. Q., Wang, Z. F., and Yan, P.: Model-Integration of Anthropogenic Heat for Improving Air Quality Forecasts over the Beijing Megacity, Aerosol Air Qual. Res., 18, 790-802, https://doi.org/10.4209/aaqr.2017.04.0155, 2017.

Yang, T., Wang, Z., Zhang, W., Gbaguidi, A., Sugimoto, N., Wang, X., Matsui, I., and Sun, Y.: Technical note: Boundary layer height determination from lidar for improving air pollution episode modeling: development of new algorithm and evaluation, Atmos. Chem. Phys., 17, 6215-6225, https://doi.org/10.5194/acp17-6215-2017, 2017.

Ye, X. X., Song, Y., Cai, X. H., and Zhang, H. S.: Study on the synoptic flow patterns and boundary layer process of the severe haze events over the North China Plain in January 2013, Atmos. Environ., 124, 129-145, https://doi.org/10.1016/j.atmosenv.2015.06.011, 2016.

Yu, H. B., Liu, S. C., and Dickinson, R. E.: Radiative effects of aerosols on the evolution of the atmospheric boundary layer, J. Geophys. Res., 107, https://doi.org/10.1029/2001jd000754, 2002.

Yu, M., Carmichael, G. R., Zhu, T., and Cheng, Y. F.: Sensitivity of predicted pollutant levels to anthropogenic heat emissions in Beijing, Atmos. Environ., 89, 169-178, https://doi.org/10.1016/j.atmosenv.2014.01.034, 2014.

Zhang, R. H., Li, Q., and Zhang, R. N.: Meteorological conditions for the persistent severe fog and haze event over eastern China in January 2013, Sci. China Earth Sci., 57, 26-35, https://doi.org/10.1007/s11430-013-4774-3, 2014.

Zhang, X. Y., Sun, J. Y., Wang, Y. Q., Li, W. J., Zhang, Q., Wang, W. G., Quan, J. N., Cao, G. L., Wang, J. Z., Yang, Y. Q., and Zhang, Y. M.: Factors contributing to haze and fog in china, Chin. Sci. Bull., 58, 1178, https://doi.org/10.1360/972013-150, 2013.

Zhang, X., Zhong, J., Wang, J., Wang, Y., and Liu, Y.: The interdecadal worsening of weather conditions affecting aerosol pollution in the Beijing area in relation to climate warming, Atmos. Chem. Phys., 18, 5991-5999, https://doi.org/10.5194/acp18-5991-2018, 2018.

Zhao, X. J., Zhao, P. S., Xu, J., Meng,, W., Pu, W. W., Dong, F., He, D., and Shi, Q. F.: Analysis of a winter regional haze event and its formation mechanism in the North China Plain, Atmos. Chem. Phys., 13, 5685-5696, https://doi.org/10.5194/acp13-5685-2013, 2013.

Zheng, Z. F., Ren, G. Y., Wang, H., Dou, J. X., Gao, Z. Q., Duan, C. F., Li, Y. B., Ngarukiyimana, J. P., Zhao, Ch. C., Chang, J., M., and Yang, Y. J.: Relationship between fineparticle pollution and the urban heat island in Beijing, China: 
observational evidence, Bound.-Lay. Meteorol., 169, 93-113, https://doi.org/10.1007/s10546-018-0362-6, 2018.

Zhong, J. T., Zhang, X. Y., Wang, Y. Q., Sun, J. Y., Zhang, Y. M., Wang, J. Z., Tan, K. Y., Shen, X. J., Che, H. C., Zhang, L., Zhang, Z. X., Qi, X. F., Zhao, H. R., Ren, S. X., and Li, Y.: Relative contributions of boundary-layer meteorological factors to the explosive growth of $\mathrm{PM}_{2.5}$ during the red-alert heavy pollution episodes in Beijing in December 2016, J. Meteor. Res., 31, 809-819, https://doi.org/10.1007/s13351-017-7088-0, 2017.
Zhong, J., Zhang, X., Wang, Y., Wang, J., Shen, X., Zhang, H., Wang, T., Xie, Z., Liu, C., Zhang, H., Zhao, T., Sun, J., Fan, S., Gao, Z., Li, Y., and Wang, L.: The two-way feedback mechanism between unfavorable meteorological conditions and cumulative aerosol pollution in various haze regions of China, Atmos. Chem. Phys., 19, 3287-3306, https://doi.org/10.5194/acp19-3287-2019, 2019. 